\title{
Very High Strain Rate Deformation Twinning Behaviour of Ti-6Al-4V
}

\author{
Steven J. Lainé ${ }^{a}$, Kevin M. Knowles ${ }^{a^{*}}$, David Rugg ${ }^{b}$ \\ ${ }^{a}$ Department of Materials Science and Metallurgy, Rolls-Royce University Technology Centre, \\ University of Cambridge, 27 Charles Babbage Road, Cambridge CB3 OFS, UK \\ ${ }^{b}$ Rolls-Royce plc, PO Box 31, Derby, DE24 8BJ, UK
}

\begin{abstract}
Equiaxed fine-grained and coarse-grained samples of h.c.p. $\alpha$ phase Ti-6Al-4V with trace amounts of retained b.c.c. $\beta$ phase were ballistically tested at room temperature. The deformed microstructures were characterised by electron back scattered diffraction. The extensive deformation twinning observed in the $\alpha$ phase in both samples was limited to the $\{10 \overline{1} 2\}$ and $\{11 \overline{2} 1\}$ tensile twinning modes. These two deformation twinning types have very different morphologies: thin $\{11 \overline{2} 1\}$ deformation twins span multiple $\alpha$ phase grain boundaries, while the wider $\{10 \overline{1} 2\}$ deformation twins are usually limited to individual grains, reorienting almost entire grains to a twinned orientation. Both $\{10 \overline{1} 2\}$ and $\{11 \overline{2} 1\}$ deformation twins are able to propagate across low angle $\alpha$ lath boundaries, but only the $\{1121\}$ deformation twinning types can propagate across high angle $\alpha$ grain boundaries.
\end{abstract}

\section{Introduction}

Plastic deformation by slip of the h.c.p. $\alpha$ phase in Ti-6wt.\%Al-4wt.\%V (Ti-6Al-4V) is dominated by prismatic $\langle a\rangle$ type slip and basal $\langle a\rangle$ type slip, but the operation of these two families of slip systems does not enable this alloy to accommodate a general change of shape without either second order $\langle c+a\rangle$ pyramidal slip operating as an additional family of slip systems or twinning operating as an additional deformation mechanism [1,2]. A number of studies have shown that room temperature deformation twinning in Ti-6Al- $4 \mathrm{~V}$ at moderate strain rates is confined mostly to

Corresponding author. E-mail address: kmk10@cam.ac.uk (K. M. Knowles).

Keywords: Ti-6Al-4V; deformation twinning; high strain rate; electron back scattered diffraction. 
$\{10 \overline{1} 2\}$ planes [2-5], although a secondary $\{1 \overline{1} 01\}$ deformation twinning mode has also been reported at these strain rates [4]. At $800{ }^{\circ} \mathrm{C}$ and the strain rates found in equal channel angular extrusion, deformation twinning is reported to be only on the $\{1 \overline{101}\}$ planes [6]. It is only at low temperatures and relatively high strain rates that a secondary $\{11 \overline{2} 1\}$ deformation twinning mode has been reported to be activated in this alloy together with the $\{10 \overline{1} 2\}$ deformation twinning mode [710]. There is no reference in the Ti-6Al-4V literature to either of the $\{11 \overline{2} 2\}$ and $\{11 \overline{2} 4\}$ modes of deformation twinning that are also observed in commercial purity (CP) titanium [11].

Interestingly, in comparison with CP titanium, twinning is observed to be noticeably less prevalent as a mode of deformation in Ti-6Al-4V $[4,6]$, to the extent that under loading conditions such as those encountered in sheet forming operations, Lütgering and Williams write that twinning in Ti-6Al$4 \mathrm{~V}$ is 'uncommon' (p. 187 of [12]). This statement is consistent with the recent experimental studies of this alloy at room temperature at moderate strain rates, where the estimated volume fraction of twins has been shown to be noticeably lower than that expected on the basis of the observed changes in texture during deformation [2-5]. One explanation to account for this discrepancy is that suggested by Prakash et al. whereby whole grains of Ti-6Al-4V are able to twin by the $\{10 \overline{1} 2\}$ deformation twinning mode [4]. These authors have suggested that this can be rationalised on the basis of whole grains being able to reorient themselves by $\{10 \overline{1} 2\}$ twin growth in a burst-like fashion [4].

As Wielewski et al. have noted [10], it is important to have a full understanding of the response of industrially important alloys such as $\mathrm{Ti}-6 \mathrm{Al}-4 \mathrm{~V}$ to possible high strain rate impact events such as 'bird strike' and 'fan blade-offs' when they are used in critical aircraft components like gas turbine engines. In their work they examined cylinders cut from $\mathrm{Ti}-6 \mathrm{Al}-4 \mathrm{~V}$ plate material subjected to a Taylor impact test [13], with an estimated peak true strain rate of $2.45 \times 10^{4} \mathrm{~s}^{-1}$. The initial material had a classic basal-transverse macrotexture, and the cylinders were cut so that their length was parallel to the rolling direction of the plate. After impact, Wielewski et al. found that $\{10 \overline{1} 2\}$ and $\{11 \overline{2} 1\}$ deformation twins formed preferentially in macrozones oriented for easy $\langle a\rangle$ type slip, so that the grains within which these twins formed were able to have contraction along the impact direction of the plate facilitated by the extension of these grains transverse to the impact direction, i.e., in the tension and contraction twin terminology used for h.c.p. metals [11,14], these tension twins cause an extension along the $c$-axis of grains, and therefore a contraction along orientations transverse to the $c$ axis. They also noted that the macrozones in $\mathrm{Ti}-6 \mathrm{Al}-4 \mathrm{~V}$, which are regions of the microstructure 
where the h.c.p. $\alpha$ phase laths have low angle misorientations with respect to one another $[10,15]$, behave during deformation in a similar manner to that of a large single $\alpha$ h.c.p. grain.

In our previous work on the very high strain rate behaviour of coarse-grained commercial purity (CP) titanium containing macrozones subjected to ballistic impact at room temperature [15], it was observed that there was deformation twinning on the $\{10 \overline{1} 2\},\{11 \overline{2} 1\},\{11 \overline{2} 2\}$ and $\{11 \overline{2} 4\}$ planes, but not on the $\{1 \overline{1} 01\}$ planes. It was also found that the deformation twinning was able to propagate from one grain to another, irrespective of whether the grain boundaries were low angle or high angle, so that all the macrozones present in the material behaved as though they were a single grain. The aim of the work reported in this paper was to apply the same methodology and analysis procedure to asreceived and heat treated $\mathrm{Ti}-6 \mathrm{Al}-4 \mathrm{~V}$ forgings, so that the deformation twinning behaviour in this forged and heat treated material when subjected to a Taylor impact test could be evaluated and compared with the behaviour found in CP titanium. Therefore, this work both complements and extends the analysis of Wielewski et al. [10] of the deformation twinning behaviour of Ti-6Al-4V plate.

\section{Experimental Details}

\subsection{Material}

A quadrant of a Ti-6Al-4V forging was provided by Timet UK Ltd. for high strain rate deformation. This alloy is one classified by Lütgering and Williams as an $\alpha+\beta$ alloy, where $\alpha$ refers to the h.c.p. form of Ti and $\beta$ the b.c.c. form [12]. As Lütgering and Williams discuss, different types of microstructure can be obtained in such alloys by changing the thermo-mechanical processing route. While the exact processing times and temperatures for the production of this forging are proprietary to Timet UK Ltd, the resultant microstructure of this forged material consisted in general of primary $\alpha$ grains $\left(\alpha_{\mathrm{P}}\right)$ and prior $\beta$ grains that were colonised with laths of fine secondary $\alpha$ grains $\left(\alpha_{\mathrm{S}}\right)$, leaving thin sub- $\mu \mathrm{m}$ thick regions of retained $\beta$ phase between the $\alpha_{\mathrm{P}}$ grains and the $\alpha_{\mathrm{S}}$ laths. Due to the different cooling rates in the large billet of the $\alpha+\beta \mathrm{Ti}-6 \mathrm{Al}-4 \mathrm{~V}$ alloy, samples from the centre of the billet had an equiaxed structure of primary $\alpha$ grains $\left(\alpha_{\mathrm{P}}\right)$, while samples from closer to the billet edge had $\alpha_{\mathrm{P}}$ and $\alpha_{\mathrm{S}}$. For the ballistic impact studies samples were taken from the centre of the billet.

To achieve material with large grains with $\alpha$ platelets separated by retained $\beta$ phase, the equiaxed microstructure was aged and furnace cooled in a similar way to the CP titanium heat treated in our 
previous work [15]. The material was encapsulated in a quartz tube with sacrificial titanium powder as an oxygen getter. The quartz tube was back-filled with inert gas. The encapsulated samples were then heated for $4 \mathrm{hr}$ at $1150{ }^{\circ} \mathrm{C}$ and subsequently furnace cooled. The as-received material had an average grain size of $12 \mu \mathrm{m}$ while the heat treated material had a $\beta$ phase grain size of approximately $2 \mathrm{~mm}$ prior to cooling, with $\alpha$-lath widths of approximately 1 to $10 \mu \mathrm{m}$ identifiable within these large prior $\beta$ grains. This coarse-grained Ti-6Al-4V was used to simulate macrozones and to have a direct comparison to our prior $\mathrm{CP}$ titanium work [15], but with retained $\beta$ phase between the $\alpha$ phase colony laths and $\alpha$ phase grains in this work.
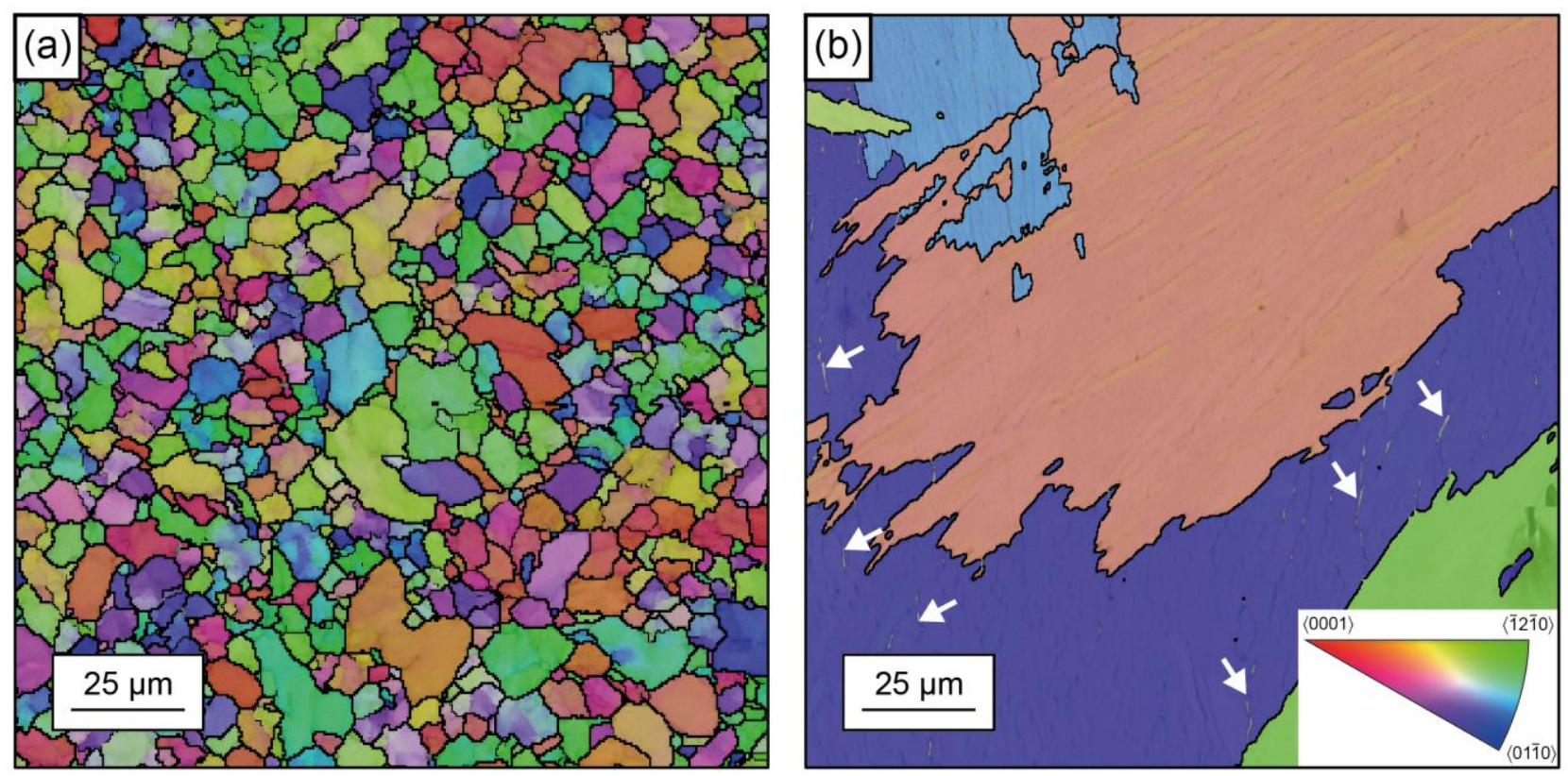

Figure 1. (a) EBSD $z$-direction inverse pole figure colouring scan of as-received $\mathrm{Ti}-6 \mathrm{Al}-4 \mathrm{~V}$ with equiaxed small grains; (b) EBSD $z$-direction inverse pole figure colouring scan of heat-treated Ti-6Al-4V with coarse grains. In both (a) and (b) there is retained $\beta$ phase, but mostly at a scale too fine to be identified by the EBSD software. However, some examples of retained $\beta$ phase are arrowed in (b). In both (a) and (b), the horizontal direction is the direction along which the cylinders used for the ballistic testing were compressed.

The difference in the microstructure of the as-received and heat treated microstructures of the samples used for ballistic testing is evident in Figures 1(a) and 1(b). In these two micrographs electron back scattered diffraction (EBSD) inverse pole figure (IPF) colour images have been used to highlight individual regions of $\alpha$ phase. In both samples there is retained $\beta$ phase, but this is mostly at too fine a scale to be identified and indexed by the EBSD acquisition system. Some examples where the fine scale retained $\beta$ phase has been identified and indexed are arrowed in Figure 1(b). The relative sizes of the primary and secondary $\alpha$ grains and the retained $\beta$ in the as-received material can be 
appreciated from the higher magnification scanning electron microscope images from closer to the billet edge shown in Figure 2. The volume fraction of retained $\beta$ is of the order of $0.1 \mathrm{wt} \%$ at most. It is very difficult to observe retained $\beta$ in EBSD maps because it is preferentially removed in the $12 \mathrm{~h}$ vibratory polishing procedure used to prepare the samples for EBSD mapping described in Section 2.2; instead samples must be observed prior to this procedure by conventional scanning electron microscopy techniques, as is shown in Figure 2(b).
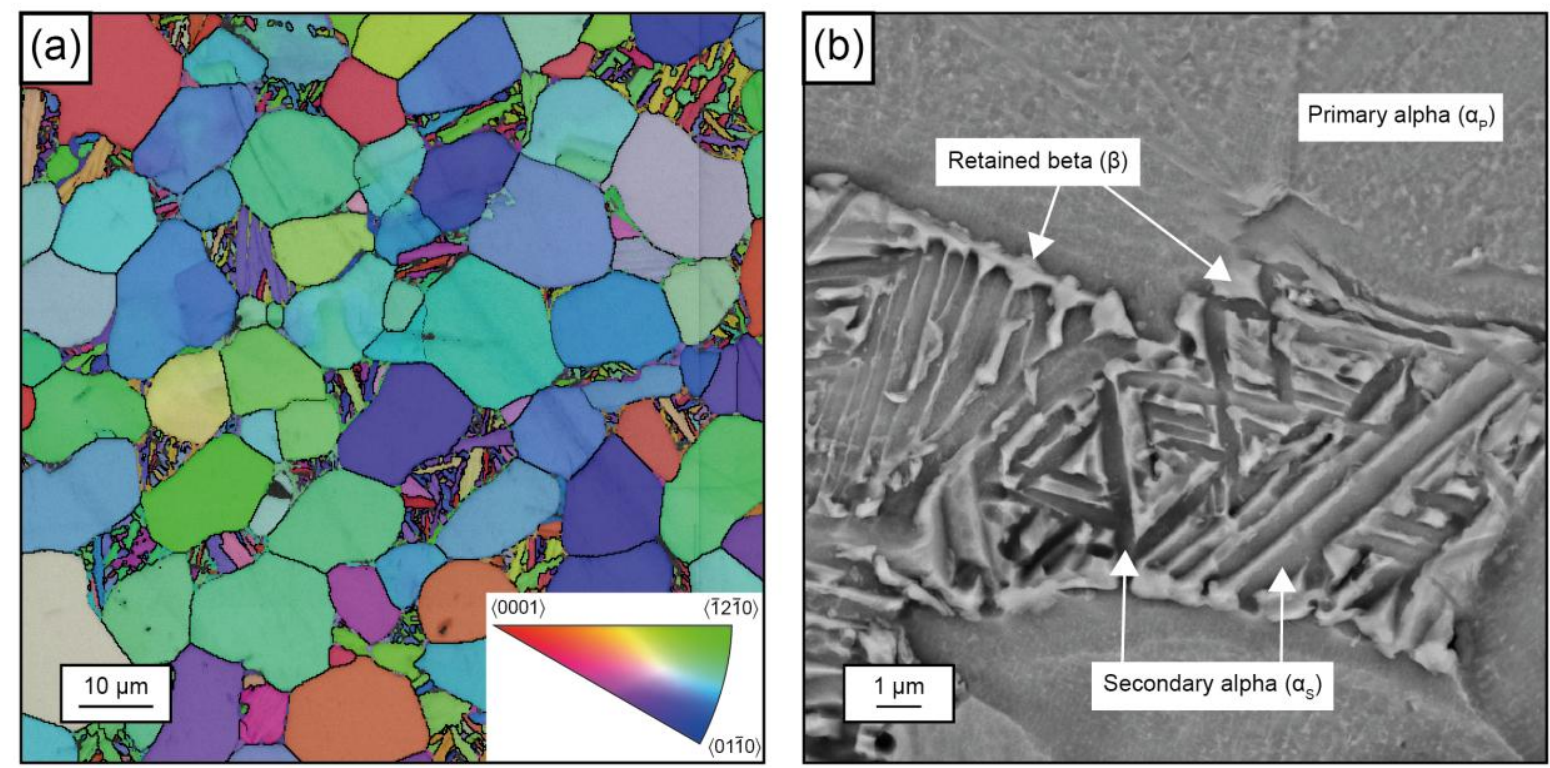

Figure 2. (a) EBSD map of Ti-6Al-4V fan blade plate material, $z$-direction inverse pole figure colouring and band contrast showing primary alpha $\left(\alpha_{\mathrm{P}}\right)$ grains of some $10 \mu \mathrm{m}$ average grain size with much finer size secondary alpha $\left(\alpha_{\mathrm{S}}\right)$ and retained beta $(\beta)$ together in pockets between the $\alpha_{\mathrm{P}}$ grains. The horizontal direction in this figure is the direction along which the cylinders used for the ballistic testing were compressed. (b) High resolution secondary electron image of etched Ti-6Al-4V fan blade plate with material $\alpha_{\mathrm{P}}, \alpha_{\mathrm{S}}$ and retained $\beta$ phases.

The presence of retained $\beta$ phase between the $\alpha$ phase platelets in Ti-6Al-4V introduces an added level of complexity relative to CP titanium, enabling the interaction of deformation twinning across $\alpha$ boundaries with retained $\beta$ phase to be evaluated. Preliminary analysis of the equiaxed forging material was also able to identify macrozones in the as-received material. An EBSD micrograph of one of these macrozones is shown in Figure 3. The almost random texture of the fine-grained asreceived $\mathrm{Ti}-6 \mathrm{Al}-4 \mathrm{~V}$ billet material was typical for forged $\mathrm{Ti}-6 \mathrm{Al}-4 \mathrm{~V}$, as is evident from the pole figures shown in Figure 4. 


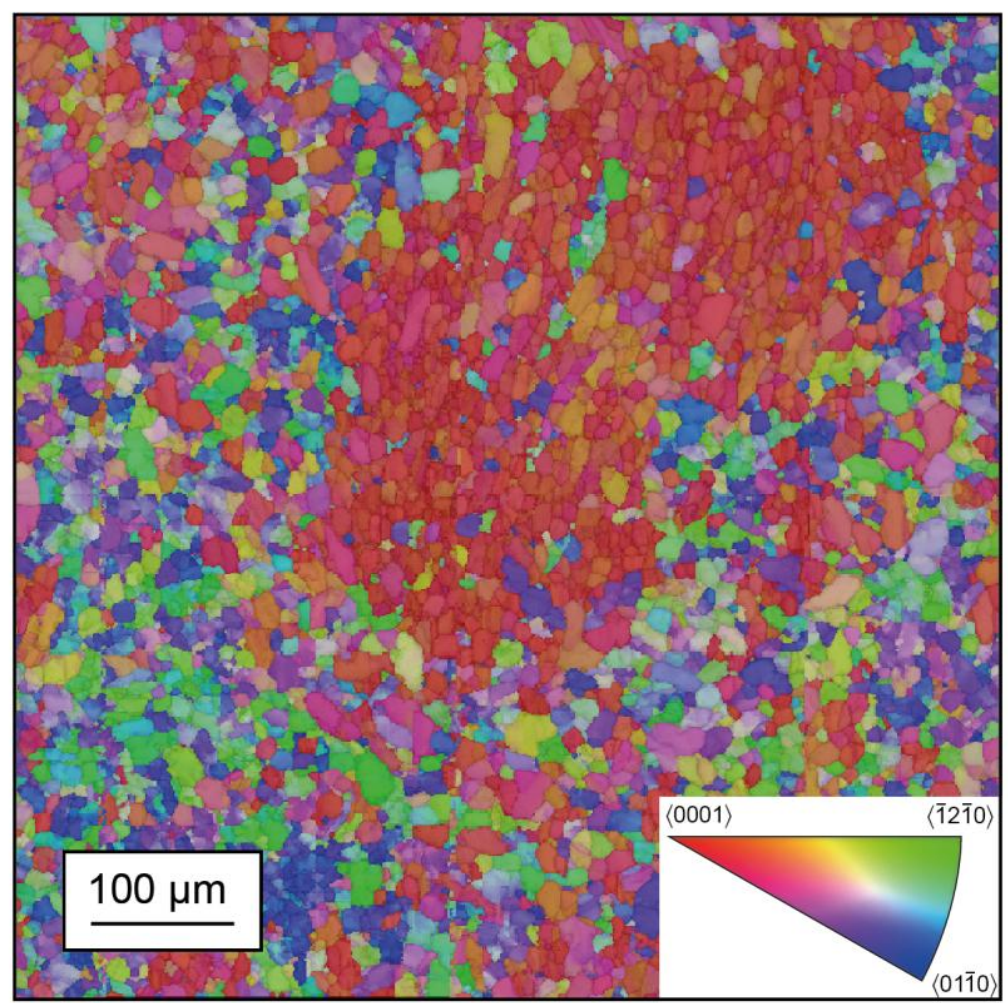

Figure 3. EBSD $z$-direction inverse pole figure colouring scan of as-received $\mathrm{Ti}-6 \mathrm{Al}-4 \mathrm{~V}$ at a lower magnification than Figure 1a. A macrozone with a $c$-axis fibre texture out of the page is evident in the top right of this scan. The horizontal direction in this figure is the direction along which the cylinders used for the ballistic testing were compressed.

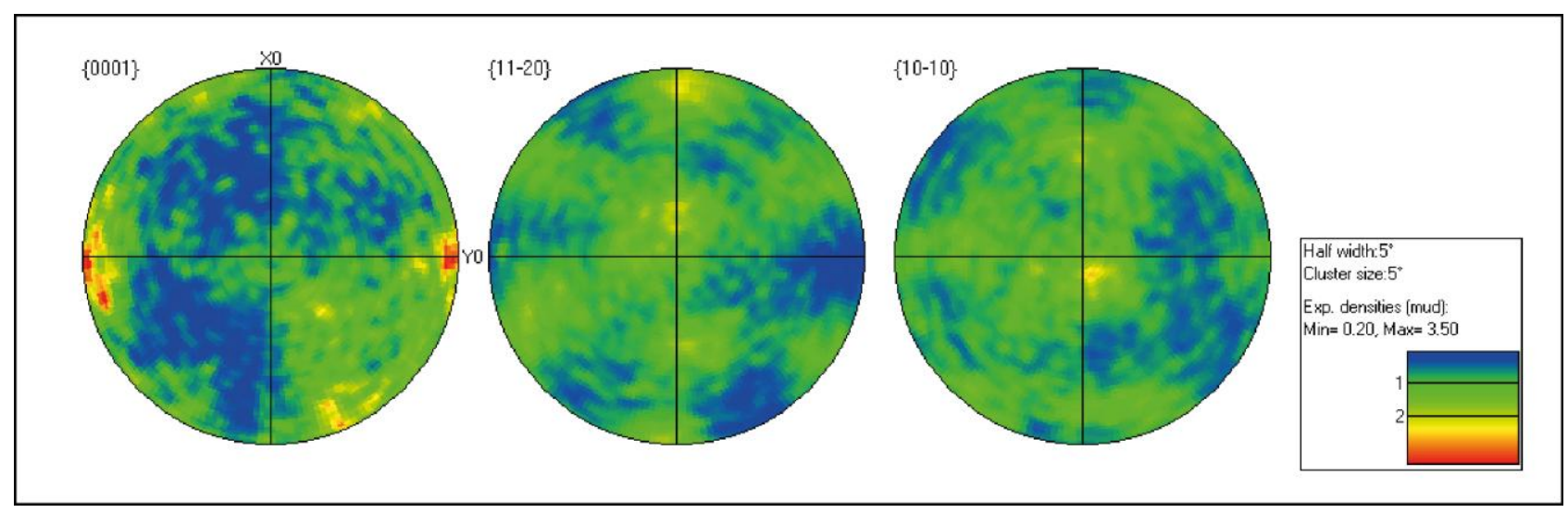

Figure 4. EBSD pole figure starting texture of as-received Ti-6Al-4V. The pole figure represents the longitudinal crosssection of the final machined projectile samples. $\mathrm{YO}$ is the direction along which the ingot is subsequently compressed. It is evident that there is a weak 0001 texture in the ingot along this direction. In the box accompanying these pole figures, the acronym mud means 'multiples of uniform distribution'. 


\subsection{Ballistic testing}

An improved version of the experimental setup used for the ballistic testing of CP titanium described in [15] was deployed for the Ti-6Al-4V ballistic experiments. A single-stage gas gun with a helium supply was used to propel cylindrical projectiles of Ti-6Al-4V towards a hardened steel target at high velocity. The $30 \mathrm{~mm}$ length and $20 \mathrm{~mm}$ diameter projectiles were carefully machined to fit the barrel of the gas gun without the need for a nylon sabot to provide a low friction seal with the barrel.

Test shots of projectiles at $250 \mathrm{~m} \mathrm{~s}^{-1}$, the velocity used in the prior work on CP titanium [15], did not always maintain projectile integrity because of the reduced ductility of $\mathrm{Ti}-6 \mathrm{Al}-4 \mathrm{~V}$ in comparison with CP titanium. However, samples propelled at the hardened steel target at approximately $200 \mathrm{~m} \mathrm{~s}^{-1}$ were all able to maintain integrity. For each of the projectiles, the moment of impact with the hardened steel target was captured using an Invisible ${ }^{\circledR}$ Vision Ultra UHSi ultra high-speed camera capable of $2 \times 10^{8}$ frames per second (fps). Laser light gate velocity measurements and the sequence of photographs acquired at the moment of impact enabled the velocity and strain rate at impact to be calculated for each projectile. The deformed cylinders were then sectioned longitudinally for microstructural analysis. Metallographic samples were prepared using standard procedures for titanium [16]. Immersion etching of polished samples in Keller's etch $(1 \% \mathrm{HF}, 1.5 \% \mathrm{HCl}, 2.5 \%$ $\mathrm{HNO}_{3}, 95 \% \mathrm{H}_{2} \mathrm{O}$ by volume) was used to highlight their microstructure. A subsequent $12 \mathrm{~h}$ vibratory polish in colloidal silica was used to prepare the samples for EBSD mapping.

\subsection{Optical microscopy and EBSD}

Regions of the samples where it was evident that there were h.c.p. $\alpha$ phase deformation twins were first identified by optical microscopy. EBSD was then used on these regions to enable the grain misorientations to be measured and the deformation twin types and deformation twinning variants to be indexed. Deformation twin variants were identified using the procedure described by Jiang et al. [17], and then checked for consistency through a comparison of misorientation between other twin types, as we have described elsewhere [11]. EBSD scans were conducted at either $20 \mathrm{kV}$ or $25 \mathrm{kV}$ using field emission gun (FEG) sources with either a CamScan MX2600 FEG scanning electron microscope (SEM) running the Oxford Instruments EBSD acquisition system, or a FEI Nova NanoSEM FEG running the Bruker EBSD acquisition system. The EBSD data was analysed using the HKL Channel 5 software package distributed by Oxford Instruments and the MTEX 4.0.9 toolbox for Matlab. Two principal methods were used for interpretation of the EBSD data: inverse pole figures and band contrast maps, also known as image quality maps [18], producing a grey scale 
colouring of the quality of the electron back-scattered pattern. On such band contrast maps, features that affect the band contrast, such as slip bands, $\alpha$ lath boundaries and grain boundaries, but also other features such as strain and surface topology, appear more black relative to the background. In identifying deformation twins using the HKL Channel 5 software, a tolerance angle of $5^{\circ}$ was used for the rotation angle of the rotation matrix required to rotate experimental twin misorientations into theoretical twin misorientations.

\section{Results and Discussion}

\subsection{Ballistic testing and modes of deformation twinning}

Four shots of Ti-6Al-4V were fired at velocities of approximately $200 \mathrm{~m} \mathrm{~s}^{-1}$, summarised in Table 1. The dynamic yield strength of the Ti-6Al-4V titanium was calculated using Equation 22 of [13] and the strain rate was estimated from analysis of the high-speed photography. For each of the four shots, the peak strain rate was estimated to have been approximately $3 \times 10^{4} \mathrm{~s}^{-1}$.

Table 1. Ti-6Al-4V ballistic test results.

\begin{tabular}{cccc}
\hline Sample & $\begin{array}{c}\text { Velocity } \\
\left(\mathbf{m ~ s}^{-\mathbf{1}}\right)\end{array}$ & $\begin{array}{c}\text { Dynamic Yield } \\
\text { Stress (MPa) }\end{array}$ & $\begin{array}{c}\text { Macro Plastic } \\
\text { Strain (\%) }\end{array}$ \\
\hline C1 & 209 & 1500 & -5.2 \\
F1 & 212 & 1620 & -4.7 \\
F2 & 217 & 1620 & -4.7 \\
F3 & 228 & 1420 & -5.4 \\
\hline
\end{tabular}

The dynamic yield strength for the coarse-grained Ti-6Al-4V (C1) was lower than the two finegrained samples that were fired at similar velocities (F1 and F2). This can be explained by the superior strength that is achieved through having smaller equiaxed grains and Hall-Petch strengthening. The dynamic yield strength for F1 and F2 was very consistent with an average of 1620 MPa. F3 was fired at a slightly higher velocity and had a lower dynamic yield and higher plastic strain. A series of six frames from the high-speed photography for samples C1, F1 and F2 are shown in Figure 5. It is evident from Figure 5 that once impact of the Ti-6Al-4V projectile is made with the target, the majority of the deformation occurs within the subsequent two frames of the high-speed camera footage. 

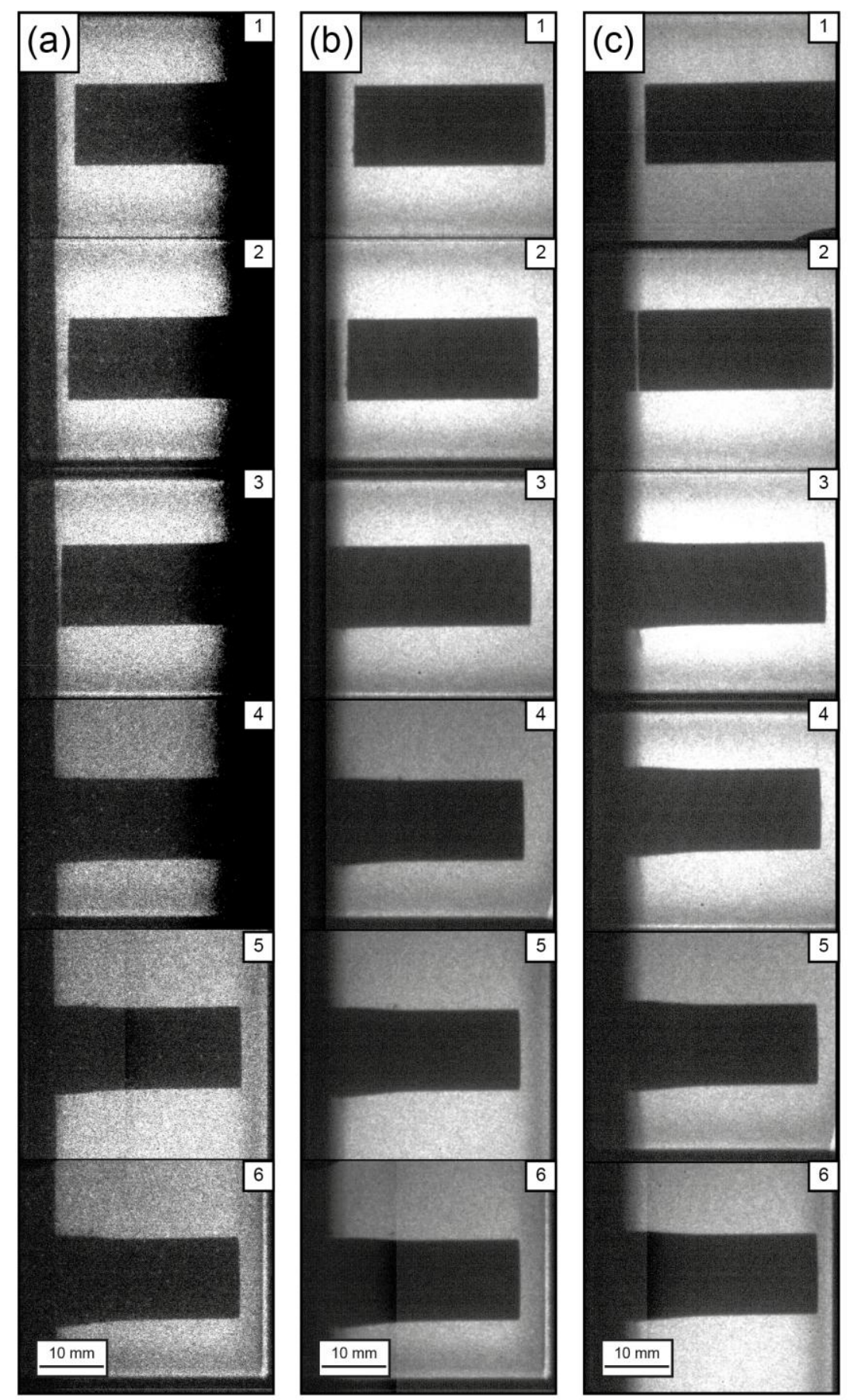

Figure 5. High-speed time-lapse photographs of $\mathrm{Ti}-6 \mathrm{Al}-4 \mathrm{~V}$ projectile impact at $150,000 \mathrm{fps}$. The photo sequence is $1-6$. The impact face is on the left hand side. (a) Coarse-grained sample C. (b) Fine-grained sample F1. (c) Fine-grained sample F2.

In both the coarse-grained and fine-grained Ti-6Al-4V samples the tensile $\{10 \overline{1} 2\}$ and $\{11 \overline{2} 1\}$ modes were the only deformation twinning modes that were observed in the sectioned projectiles. There was no evidence of $\{11 \overline{2} 2\}$ or $\{11 \overline{2} 4\}$ compression twins seen in similarly deformed CP titanium [15], nor was there any evidence of $\{1 \overline{1} 01\}$ deformation twins. Therefore, our results are consistent 
with the observations on Ti-6Al-4V plate made at similar ballistic strain rates by Wielewski et al. [10]. EBSD micrographs from $\mathrm{C} 1$ and F2 are shown in Figures 6 and 7 respectively. These micrographs were taken from very close to the impact face where the extent of plastic strain is the highest, in contrast to our previous work on $\mathrm{CP}$ titanium at distances on a deformed projectile further away from the impact face where the local strain rate was lower by a factor of $\sim 10[11,15]$.

Of the five possible deformation twinning modes which occur in $\mathrm{CP}$ titanium, the two tensile $\{10 \overline{1} 2\}$ and $\{11 \overline{2} 1\}$ twinning modes have the lowest shuffle complexities, $q$, of 4 and 2 respectively $[11,19,20]$ while $\{10 \overline{1} 2\}$ also has the lowest shear magnitude of 0.174 . However, the $q=2\{1121\}$ deformation twinning mode has a noticeably higher shear magnitude (0.630) than the $q=6\{11 \overline{2} 2\}$ and $\{11 \overline{2} 4\}$ deformation twinning modes (both 0.219 ) or the $q=8\{1 \overline{1} 01\}$ deformation twinning mode (0.099) reported in CP titanium.

Recent work by Fitzner et al. [21,22] at strain rates used of $10^{-3} \mathrm{~s}^{-1}$ has examined deformation twinning as a function of $\mathrm{Al}$ content in $\mathrm{Ti}-\mathrm{Al}$ alloys for alloying additions of $\mathrm{Al}$ from 0 wt.\% up to 8 wt.\% Al. In these alloys, the dominant twinning mode by some margin was found to be the $\{10 \overline{1} 2\}$ tensile twinning mode, increasing in activity from 0 to $4 \mathrm{wt} . \% \mathrm{Al}$, and then decreasing towards $6 \mathrm{wt} . \%$ Al. Above 6 wt.\% Al the twinning activity decreased further, resulting in an almost complete suppression of twin activity at $8 \mathrm{wt} \% \mathrm{Al}$. A small fraction of $\{11 \overline{2} 1\}$ tensile twinning was also reported in these $\mathrm{Ti}-\mathrm{Al}$ alloys, increasing as the wt.\% $\mathrm{Al}$ increased [22]. The experimental evidence from $\mathrm{Ti}-6 \mathrm{Al}-4 \mathrm{~V}$ alloys from here and elsewhere $[2-5,10]$ therefore suggests that at strain rates of the order of $10^{-3} \mathrm{~s}^{-1},\{11 \overline{2} 1\}$ deformation twins are suppressed in $\mathrm{Ti}-6 \mathrm{Al}-4 \mathrm{~V}$ relative to $\mathrm{Ti}-6 \mathrm{Al}$, only becoming active in Ti-6 Al- $4 \mathrm{~V}$ when the strain rate is increased to a rate of the order of $10^{4} \mathrm{~s}^{-1}$. This deformation mode would seem to be selected at very high strain rates in $\mathrm{Ti}-6 \mathrm{Al}-4 \mathrm{~V}$ on the basis of the relatively simple shuffles required to carry all the atoms in the twinned structure into their correct positions within the timescale imposed by the strain rate, rather than on the basis of its shear magnitude. 

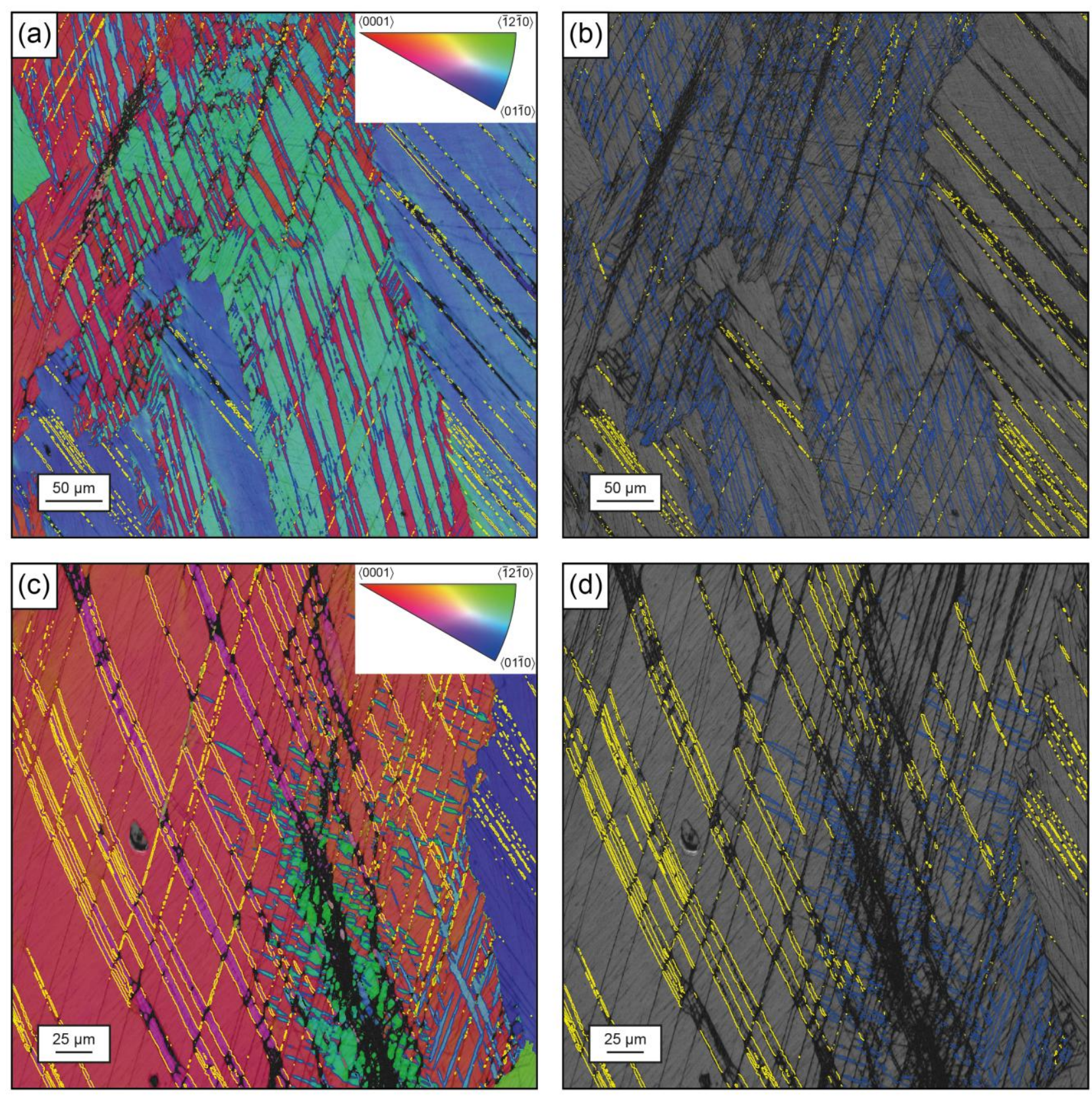

Figure 6. EBSD scans of coarse-grained Ti-6Al-4V ballistic sample $\mathrm{C} 1,1 \mathrm{~mm}$ away from the impact face at $25 \mathrm{kV}$ with a $0.3 \mu \mathrm{m}$ step size. The loading direction is in the horizontal direction. $\{10 \overline{1} 2\}$ deformation twins are outlined in blue and $\{11 \overline{2} 1\}$ deformation twins are outlined in yellow. (a) and (c) $z$-direction inverse pole figure colouring and band contrast with the twin boundaries coloured. (b) and (d) The same regions with band contrast and the twin boundaries coloured. It is evident from an inspection of these EBSD scans that the deformation twins are typically $<5 \mu \mathrm{m}$ thick; twins $\sim 1 \mu \mathrm{m}$ or less in thickness are therefore defined by their outlines alone, whereas thicker twins such as the $\{10 \overline{1} 2\}$ twins in the aquamarine grain in (a) are coloured in red and also outlined in blue. 

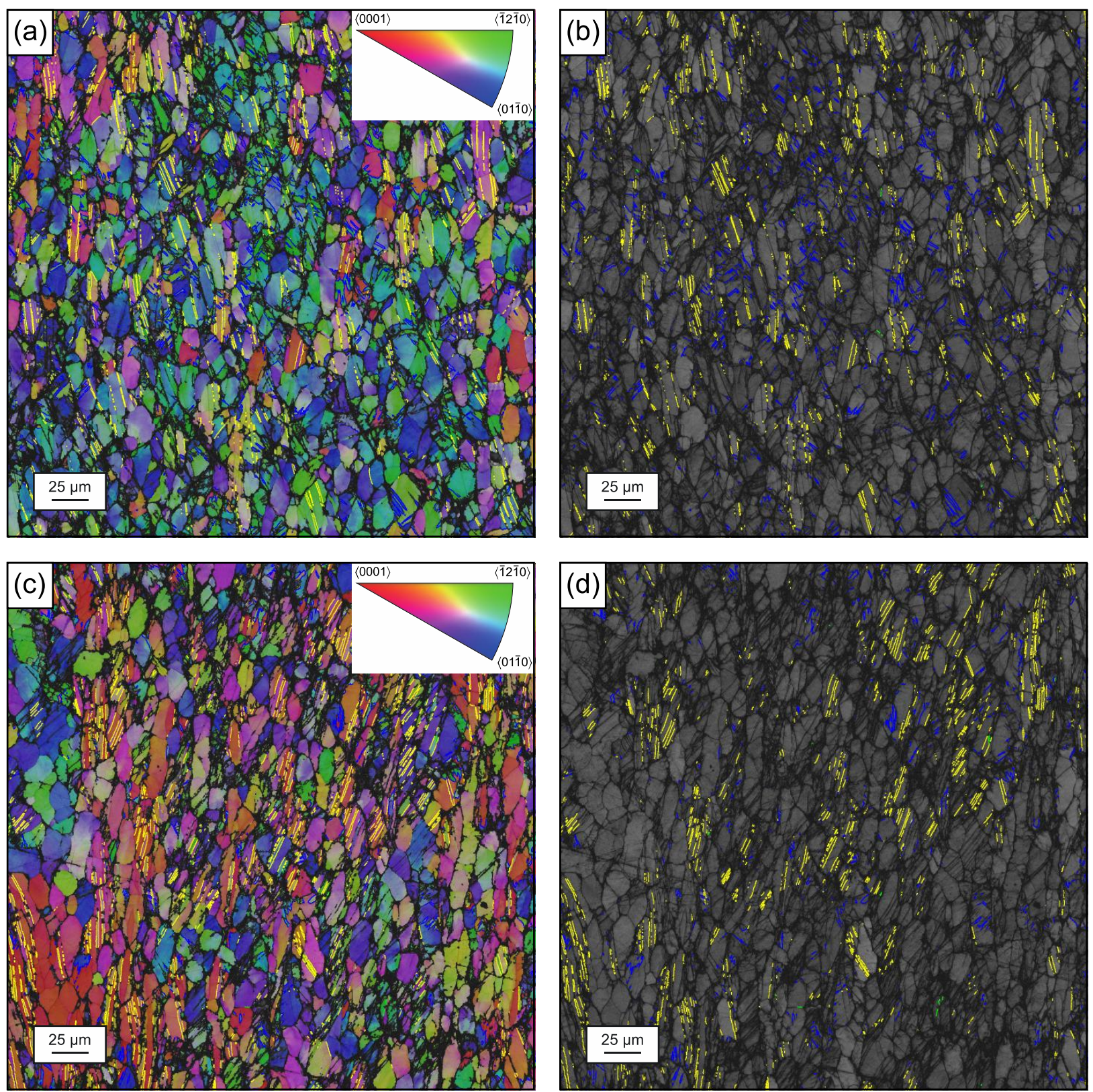

Figure 7. EBSD scans of fine-grained Ti-6Al-4V ballistic sample (Sample F2), $1 \mathrm{~mm}$ away from the impact face at $25 \mathrm{kV}$ with a $0.3 \mu \mathrm{m}$ step size. The loading direction is in the horizontal direction. $\{10 \overline{1} 2\}$ deformation twins are outlined in blue and $\{11 \overline{2} 1\}$ deformation twins are outlined in yellow. (a) and (c) z-direction inverse pole figure colouring and band contrast with the twin boundaries coloured. $55 \%$ of the deformation twin traces are indexed as $\{10 \overline{1} 2\}$ and $45 \%$ are indexed as $\{11 \overline{2} 1\}$. (b) and (d) The same regions with band contrast and the twin boundaries coloured. $38 \%$ of the deformation twin traces are indexed as $\{10 \overline{1} 2\}$ and $62 \%$ are indexed as $\{11 \overline{2} 1\}$. 
Further evidence that the only deformation twinning modes observed at these very high strain rates are the $\{10 \overline{1} 2\}$ and $\{11 \overline{2} 1\}$ tensile twinning modes is shown in Figure 8. In this region of sample $\mathrm{C} 1$, there are four $\alpha$-lath colonies: A, B, C and D. The turquoise region to the right of $\mathrm{C}$ is the one at the top left of Figure 6. At the level of resolution attained by the EBSD equipment, it is apparent that A in Figure 8 remains free from deformation twinning, even though B, C and D have clearly deformed by either $\{10 \overline{1} 2\}$ and / or $\{11 \overline{2} 1\}$ deformation twinning.
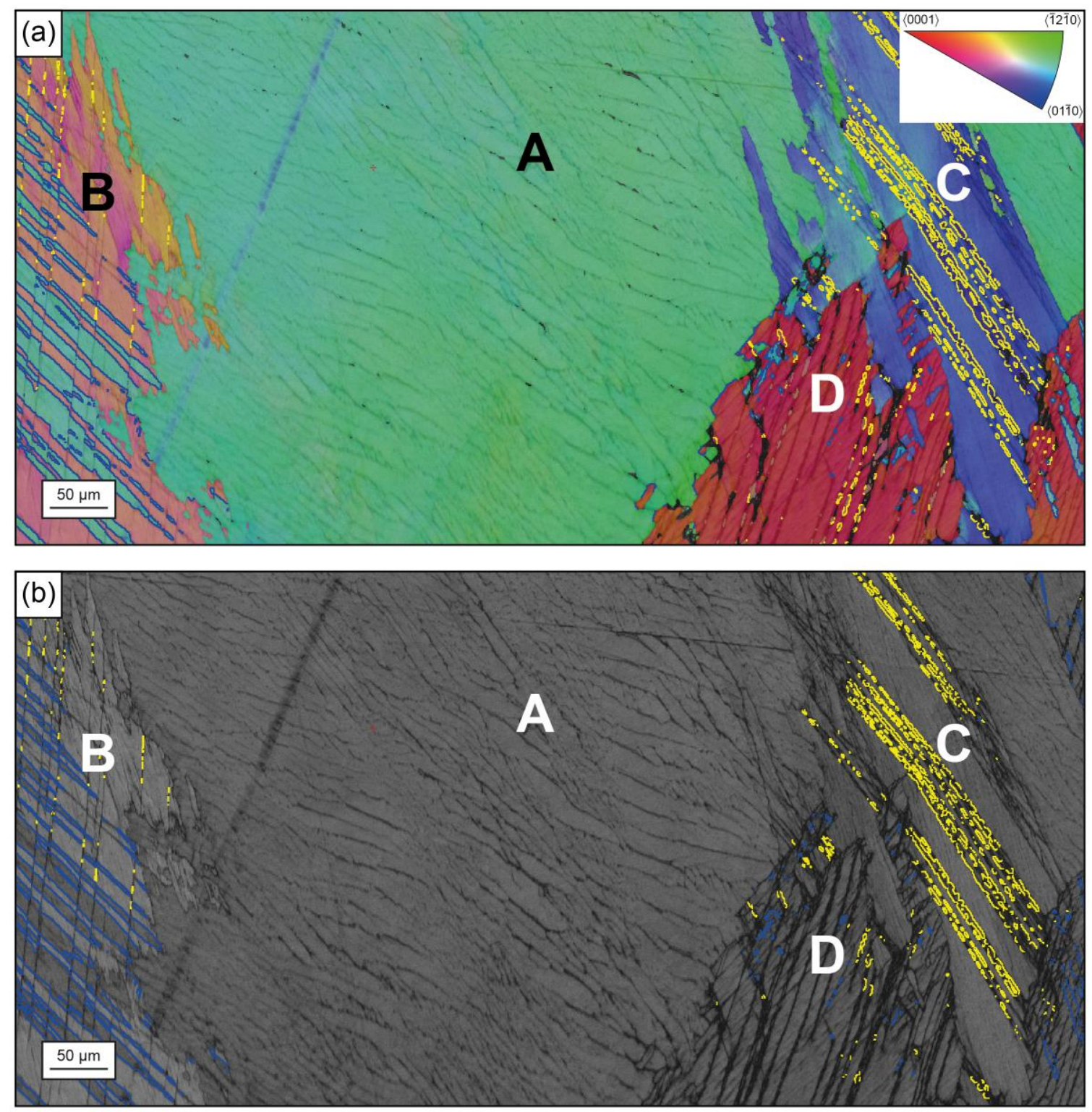

Figure 8. EBSD scan of coarse-grained Ti-6Al-4V ballistic sample (Sample C1) taken to the left of Figure 5, $1 \mathrm{~mm}$ away from the impact face at $25 \mathrm{kV}$ with a $0.3 \mu \mathrm{m}$ step size. The loading direction is in the horizontal direction. $\{10 \overline{1} 2\}$ deformation twins are outlined in blue and $\{11 \overline{2} 1\}$ deformation twins are outlined in yellow. (a) $z$-direction inverse pole figure colouring and band contrast with the twin boundaries coloured and $\alpha$ lath colonies labelled A, B, C and D. (b) The same region with band contrast and the twin boundaries coloured. 
The maximum Schmid factors for the $\{10 \overline{1} 2\},\{11 \overline{2} 1\},\{11 \overline{2} 2\},\{11 \overline{2} 4\}$ and $\{1 \overline{1} 01\}$ deformation twinning types for the four $\alpha$ lath colonies labelled in Figure 8 are listed in Table 2. For deformation twinning it is possible to have negative Schmid factors because the direction of shear is specific: unlike slip, it is not reversible. Furthermore, when the $c$-axis of a grain or colony is within $10^{\circ}$ or so of the direction of compression, there is little spread in the Schmid factors for the different possible variants within the family of a deformation twinning mode, as we have demonstrated in our prior work on CP titanium [11]. It is striking that A has a negative Schmid factor for the $\{10 \overline{1} 2\}$ and $\{11 \overline{2} 1\}$ tension twinning modes precisely because for this colony the $c$-axis is aligned with the loading direction. However, even though they all have high positive Schmid factors, none of the three compression twinning modes possible in CP titanium, $\{11 \overline{2} 2\},\{11 \overline{2} 4\}$ and $\{1 \overline{1} 01\}$, were activated in this Ti-6Al-4V colony.

Table 2. Highest Schmid factors for twinning within each possible deformation twinning mode for the $\alpha$ lath colonies shown in Figure 8, assuming plane strain compression loading in the $x$-direction, which is horizontal across the page in each of these figures, compressing the crystal $c$-axis for suitably oriented grains. The observed operative twinning modes are in bold.

\begin{tabular}{ccccc} 
Deformation & \multicolumn{4}{c}{ Highest Schmid Factor, $x$-direction, plane strain } \\
Twin Mode & Colony A & Colony B & Colony C & Colony D \\
\hline$\{10 \overline{1} 2\}$ & -0.46 & $\mathbf{0 . 4 4}$ & 0.34 & $\mathbf{0 . 4 6}$ \\
$\{11 \overline{2} 1\}$ & -0.44 & $\mathbf{0 . 4 0}$ & $\mathbf{0 . 4 7}$ & $\mathbf{0 . 3 8}$ \\
$\{11 \overline{2} 4\}$ & 0.48 & -0.39 & -0.40 & -0.46 \\
$\{11 \overline{2} 2\}$ & 0.49 & -0.42 & -0.44 & -0.46 \\
$\{10 \overline{1} 1\}$ & 0.50 & -0.49 & -0.45 & -0.46 \\
\hline
\end{tabular}

The analysis of the fine-grained $\mathrm{Ti}-6 \mathrm{Al}-4 \mathrm{~V}$ also revealed an absence of the three compression twinning modes. In Figure 7(a) there are multiple fine grains that have a high Schmid factor for compression twinning modes. The grains that have their $c$-axis aligned within $10^{\circ}$ of the compressive loading direction are highlighted in green in Figure 9. It is interesting that some of the grains favourably oriented for compression twinning modes had actually deformed by $\{10 \overline{1} 2\}$ deformation twinning even though the Schmid factor for $\{10 \overline{1} 2\}$ deformation twinning is low (negative). Such occurrences of non-Schmid based twin selection in the fine-grained material can only be rationalised on the basis of their local stress state being different to the macroscopic stress state. 
The observation that only two deformation twinning modes are seen to operate in $\mathrm{Ti}-6 \mathrm{Al}-4 \mathrm{~V}$ at high strain rates has implications for its ability to deform plastically. Although these deformation twinning modes and slip together help plastic deformation to occur for suitably oriented grains, unfavourably oriented grains / $\alpha$ lath colonies such as those seen in Figures 6-9 where twinning does not occur, and where the $c$-axes is aligned closely to the compressive loading direction, are likely to be noticeably less deformable plastically than the surrounding grains. This is because it is generally accepted that the second order pyramidal $\langle c+a\rangle$ slip is difficult to activate in h.c.p. metals, as Preuss et al. have noted [2]. Therefore, deformation leading to a shape change with a component in the $c$ direction will not be possible without the operation of compressive twinning modes, such as the ones which can operate at very high rates of strain in CP titanium [15]. This will help to explain the reduced plasticity of ballistically tested $\mathrm{Ti}-6 \mathrm{Al}-4 \mathrm{~V}$ when compared to $\mathrm{CP}$ titanium.

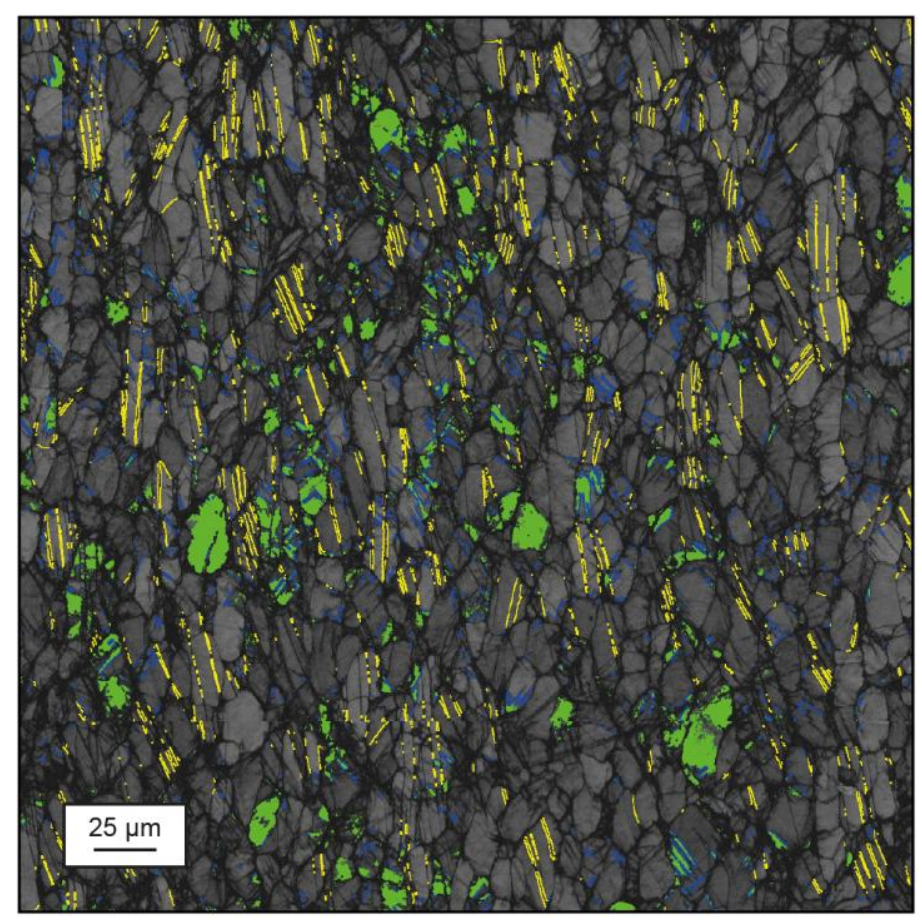

Figure 9. EBSD scan from Figure 7(a). The grains that have their $c$-axis aligned within $10^{\circ}$ of the compressive loading direction are highlighted in green. The loading direction is in the horizontal direction.

In Figures 6(a) and 6(b) the two different large grains evident in the micrographs are deformed predominantly by high volume fractions of $\{10 \overline{1} 2\}$ twins in the red $\alpha$ lath colony (prior $\beta$ grain) and $\{11 \overline{2} 1\}$ twins in the blue $\alpha$ lath colony. This result is consistent with the maximum Schmid factor for $\{10 \overline{1} 2\}$ and $\{11 \overline{2} 1\}$ in each grain. The red $\alpha$ lath colony has a maximum Schmid factor of 0.44 for $\{10 \overline{1} 2\}$ deformation twinning and 0.36 for $\{11 \overline{2} 1\}$ deformation twinning, whereas the blue $\alpha$ lath 
colony has a maximum Schmid factor of 0.39 for $\{10 \overline{1} 2\}$ deformation twinning and 0.46 for $\{11 \overline{2} 1\}$ deformation twinning. These findings are consistent with a Schmid-based twin type selection for these two possible families of twinning modes.

In Figures 6(c) and 6(d) the large red $\alpha$ lath colony that covers the majority of the scan area has deformed by both $\{10 \overline{1} 2\}$ and $\{11 \overline{2} 1\}$ deformation twinning. There are two predominant variants of long narrow $\{11 \overline{2} 1\}$ deformation twins activated that span the entire colony. One of these $\{11 \overline{2} 1\}$ variants runs from the lower right to the upper left and is easily recognisable in both Figure 6(c) and $6(d)$; the other $\{11 \overline{2} 1\}$ variant, running from the lower left to the upper right, is more visible in Figure 6(c) than Figure 6(d). Much shorter $\{10 \overline{1} 2\}$ twins span some of the regions of the parent grain between the $\{11 \overline{2} 1\}$ twin traces. The morphology of the two different twin types suggests that the colony first deformed by $\{11 \overline{2} 1\}$ deformation twinning and subsequently deformed by $\{10 \overline{1} 2\}$ twinning.

However, Schmid factor analysis of this colony would suggest that it was more likely to deform first by $\{10 \overline{1} 2\}$ deformation twinning. The factor is 0.46 for $\{10 \overline{1} 2\}$ twinning and 0.38 for $\{11 \overline{2} 1\}$ twinning. The difference in the Schmid factors is small, so $\{11 \overline{2} 1\}$ twinning may have initially been favoured by other factors, such as the more simple $q=2$ shuffle complexity, giving rise to a lower critically resolved shear stress and /or nucleation/growth propagation stress to activate $\{11 \overline{2} 1\}$ twinning before $\{10 \overline{1} 2\}$ twinning under these very high strain rate conditions. Alternatively, the local stress state may have altered as macroscopic deformation proceeded to favour $\{10 \overline{1} 2\}$ twinning over $\{11 \overline{2} 1\}$ twinning once a certain amount of $\{11 \overline{2} 1\}$ twinning had propagated, or the creation of $\{10 \overline{1} 2\}$ twins may have become more favourable energetically than the generation of more $\{11 \overline{2} 1\}$ twins.

It is evident from the fine-grained results shown in Figure 7 that at very high strain rates there is a significant proportion of $\{11 \overline{2} 1\}$ deformation twinning present in $\mathrm{Ti}-6 \mathrm{Al}-4 \mathrm{~V}$, consistent with the data shown in Figure 4(b) of [10]. In Figures 7(a) and 7(b) 55\% of the deformation twin traces are indexed as $\{10 \overline{1} 2\}$ and $45 \%$ are indexed as $\{11 \overline{2} 1\}$, whereas in Figures $7(\mathrm{c})$ and $7(\mathrm{~d}), 38 \%$ of the deformation twin traces are indexed as $\{10 \overline{1} 2\}$ and $62 \%$ are indexed as $\{11 \overline{2} 1\}$. These data further emphasis the preference for Ti-6Al-4V to twin on $\{11 \overline{2} 1\}$ planes at very high strain rates. As Gray has noted [7,9] and others have modelled using computer simulation techniques [23,24], $\{11 \overline{2} 1\}$ twins in h.c.p. metals have highly glissile interfacial steps (twinning dislocations), it is evident that this may be the 
underlying reason for the high fraction of $\{11 \overline{2} 1\}$ twinning observed at these very high strain rates in Ti-6Al-4V.

\subsection{Deformation twinning interactions across $\alpha$ phase grain boundaries}

A key finding from ballistic testing of $\mathrm{CP}$ titanium was the ability for deformation twins to interact across $\alpha$ phase grain boundaries [11]. Detailed examination of the ballistically tested Ti-6Al-4V revealed similar grain boundary interactions in both the coarse-grained and fine-grained samples.

\subsubsection{Coarse-grained Ti-6Al-4V results}

Following the ballistic testing, deformation twin traces were readily observed spanning $\alpha$ lath colonies and appearing to go directly though $\alpha$ laths as though their grain boundaries were nonexistent and presented no barrier to the propagation of deformation twins. This can be seen in the examples at higher magnification shown in Figure 10, and in the other EBSD scans of the coarsegrained Ti-6Al-4V at lower magnifications shown in Figures 6 and 11, where the $\alpha$ lath boundaries are more easily visible in the band contrast layer of the EBSD data. Even after careful analysis of the band contrast and the inverse pole figure colouring in these ballistically deformed samples, in a number of cases it was difficult to establish beyond doubt whether features highlighted by the band contrast are (i) twins which the software had been unable to index, (ii) slip bands, or (iii) $\alpha$ lath boundaries. Some unambiguous examples of low angle $\alpha$ lath boundaries are arrowed in Figure 10. High grain boundary angle interactions between $\alpha$ lath colony boundaries were also observed in the coarse-grained material, some of which are shown in Figure 11, where it is apparent that some of the $\{11 \overline{2} 1\}$ deformation twins appear to propagate across high angle $\alpha$ grain boundaries, while in other cases the offsets seen between different twins at the $\alpha$ grain boundaries suggest that direct propagation does not occur, but that instead indirect propagation occurs whereby new sets of twins are nucleated in one $\alpha$ grain as a consequence of the presence of deformation twins in the other.

A detailed crystallographic analysis of the grain boundary disorientation geometry in Figure 11 confirms that these $\alpha$ grains are all very likely to originate from a single high temperature $\beta$ grain (Appendix A). Overall, the evidence here would suggest that it is more likely that, even with this very favourable crystallography, the stress ahead of a propagating twin in one $\alpha$ grain causes nucleation and then growth of a twin, or sets of twins, in an adjacent $\alpha$ grain during high strain rate deformation, 
rather than the deformation twins propagate from one $\alpha$ grain to the other across what are actually rather special high-angle $\alpha$ grain boundaries.

\subsubsection{Fine-grained Ti-6Al-4V results}

The coarse-grained Ti-6Al-4V provided a method of observing how deformation twinning interacts with low angle grain boundaries in $\alpha$ lath colonies. This fine-grained material also contained real macrozones that were identified in the as-received $\mathrm{Ti}-6 \mathrm{Al}-4 \mathrm{~V}$, such as the one shown in Figure 3 . An EBSD scan acquired close to the impact face of sample F1 revealed a macrozone where a large number of the grains had deformed by $\{11 \overline{2} 1\}$ tensile twinning. Chains of $\{11 \overline{2} 1\}$ deformation twin traces were observed interacting across a large number of grains with a range of relatively low misorientations, as shown in Figure 12.

There were many more occurrences of deformation twin interactions across $\alpha$ phase grain boundaries with a range of misorientation angles. Macrozones and textured regions exhibited the most deformation twin interactions. A relatively large area scan with some textured regions containing concentrations of $\{11 \overline{2} 1\}$ deformation twins interacting across grain boundaries is shown in Figure 13.

Some typical examples of grain boundary interactions are shown in Figure 14. The majority of grain boundary interactions consisted of $\{11 \overline{2} 1\}$ deformation twins. However, there were also some examples of $\{11 \overline{2} 1\}-\{10 \overline{1} 2\}$ twin interactions, one of which is shown in Figure 14(j). The wide range of grain boundary misorientation angles is evident from the tabulated results in Table 3 of the misorientation angles for the highlighted grain pairs with deformation twinning interactions in Figure 14. The misorientation angles range from $8^{\circ}$ to $65^{\circ}$. 

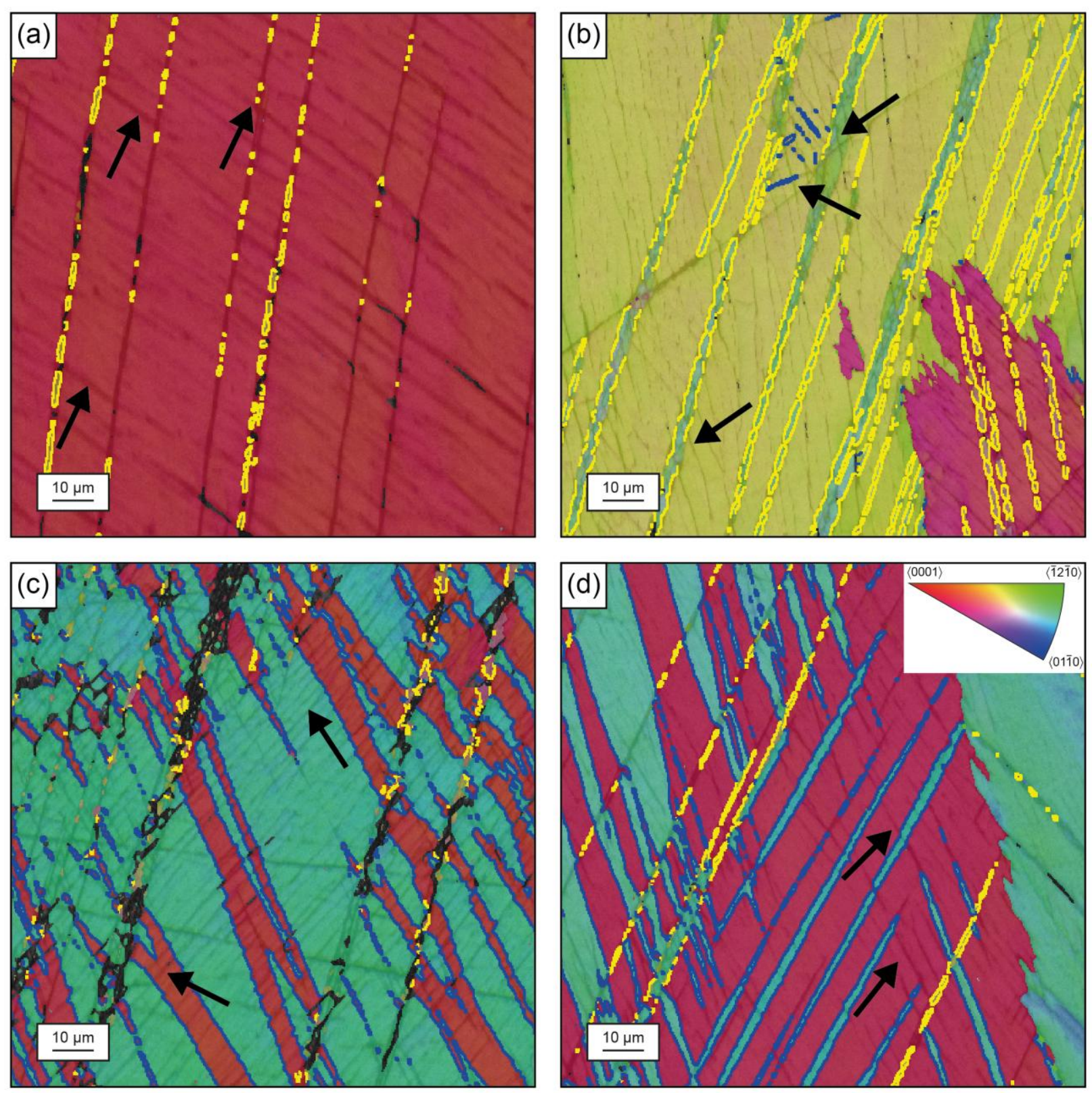

Figure 10. EBSD scan of the coarse-grained Ti-6Al-4V ballistic sample (Sample C1), at $25 \mathrm{kV}$ with a $0.3 \mu \mathrm{m}$ step size. The loading direction is in the horizontal direction. $z$-direction inverse pole figure colouring and band contrast with $\{10 \overline{1} 2\}$ deformation twins are outlined in blue and $\{11 \overline{2} 1\}$ deformation twins are outlined in yellow. (a) and (b) $\{11 \overline{2} 1\}$ deformation twin traces crossing low angle $\alpha$ lath boundaries, some examples of which are arrowed. In (b) some smaller $\{10 \overline{1} 2\}$ deformation twin traces spanning the gap between $\{11 \overline{2} 1\}$ deformation twin traces cross low angle $\alpha$ lath boundaries. (c) and (d) $\{10 \overline{1} 2\}$ deformation twin traces crossing low angle $\alpha$ lath boundaries, some examples of which are arrowed. 

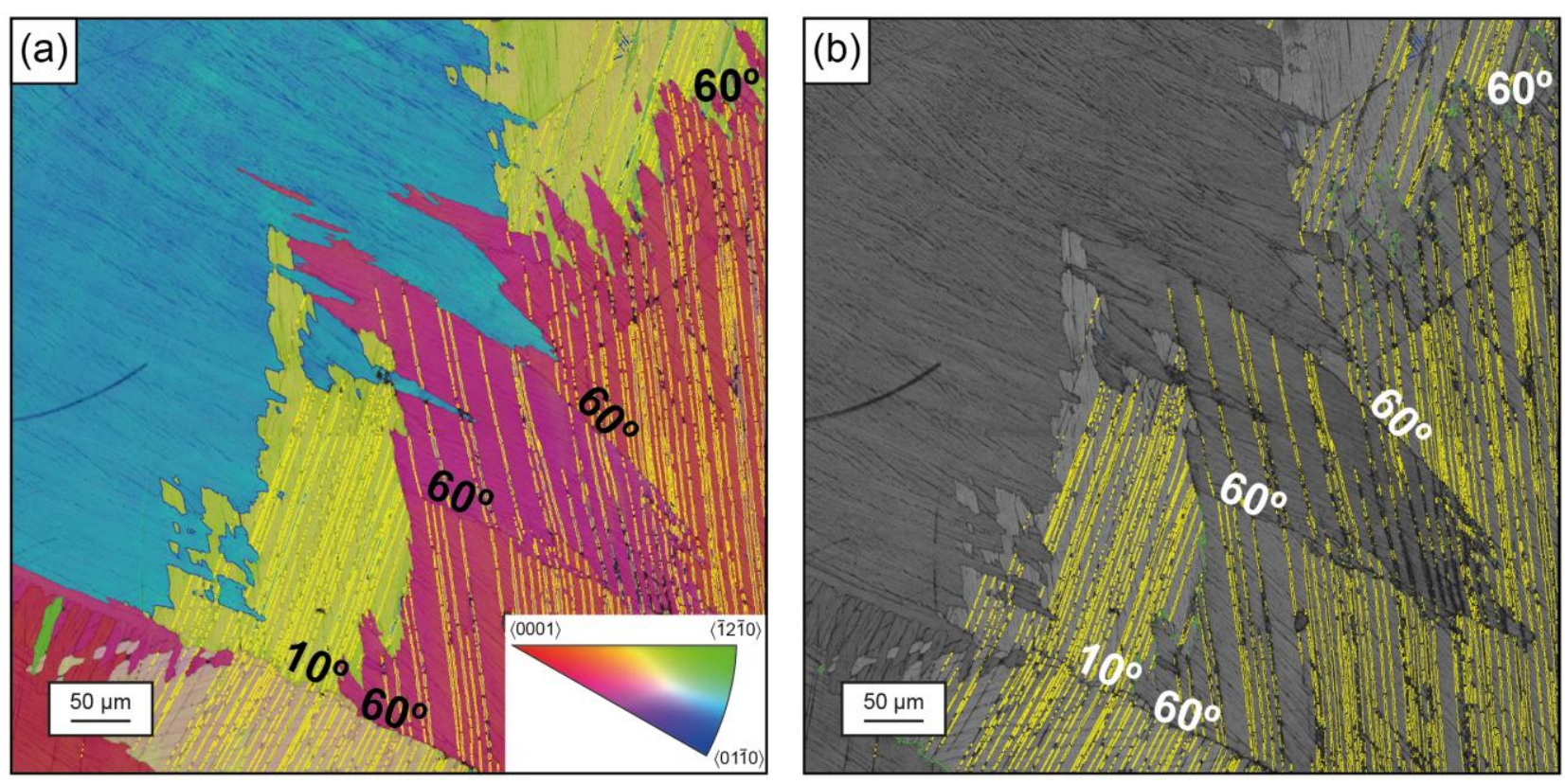

Figure 11. EBSD scan of coarse-grained Ti-6Al-4V ballistic sample (Sample C1), $3 \mathrm{~mm}$ away from the impact face at 25 $\mathrm{kV}$ with a $0.3 \mu \mathrm{m}$ step size. The loading direction is in the horizontal direction. $\{11 \overline{2} 1\}$ deformation twins are outlined in yellow. (a) $z$-direction inverse pole figure colouring and band contrast with twin boundaries coloured and the grain boundary misorientation angles labelled. (b) same region with band contrast with twin boundaries coloured and the grain boundary misorientation angles labelled. 

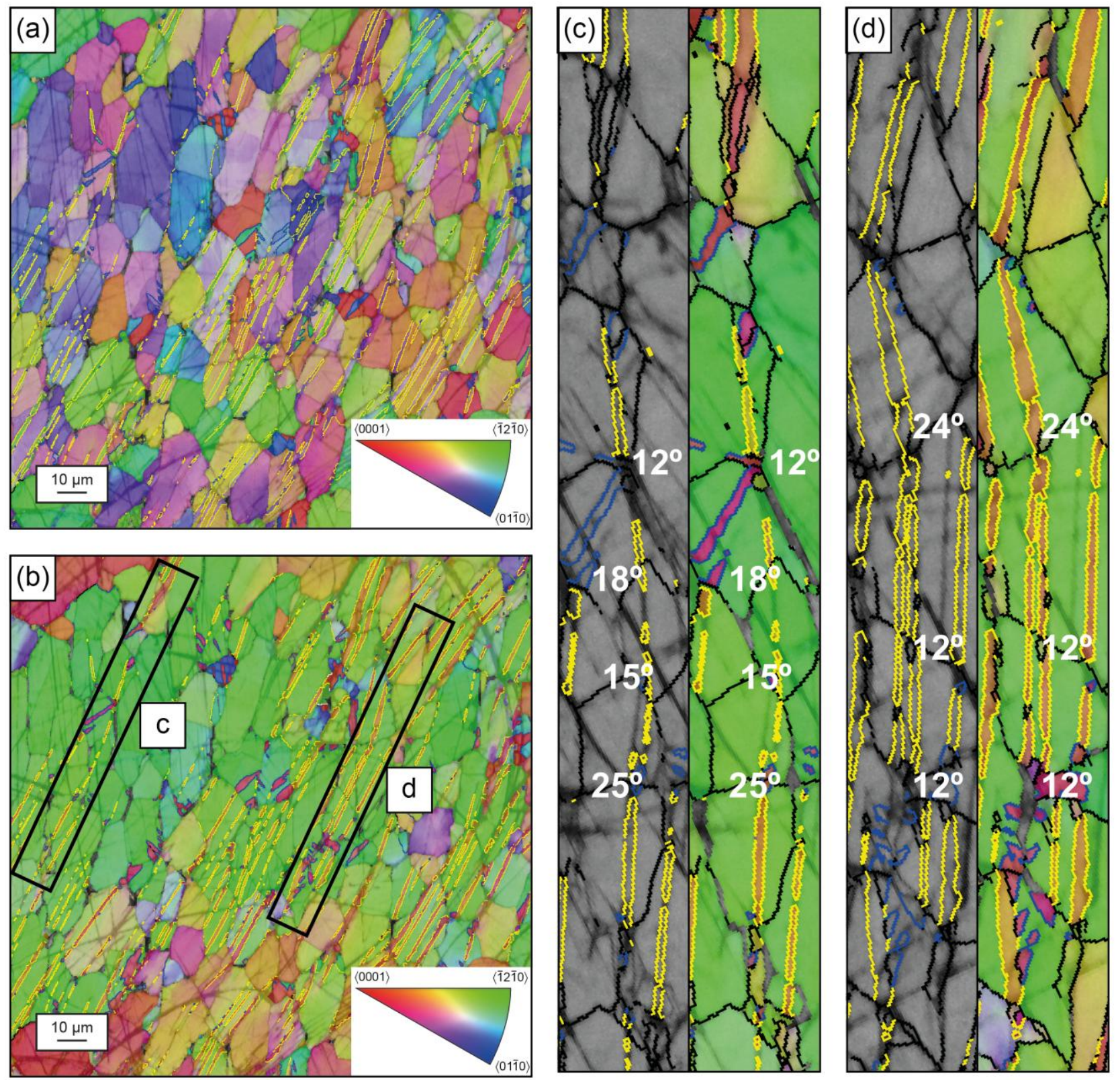

Figure 12. EBSD scan of fine-grained Ti-6Al-4V ballistic sample (Sample F1), $1 \mathrm{~mm}$ away from the impact face at $25 \mathrm{kV}$ with a $0.3 \mu \mathrm{m}$ step size. The loading direction is in the horizontal direction in (a) and (b). $\{10 \overline{1} 2\}$ deformation twins are outlined in blue and $\{11 \overline{2} 1\}$ deformation twins are outlined in yellow. (a) $z$-direction inverse pole figure colouring in the $z$ direction and band contrast with the twin boundaries coloured. (b) Same region but with inverse pole figure colouring in the $x$-direction to highlight the macrozone better. Here, the macrozone is coloured green. (c) and (d) Boxed regions from (b) with misorientation angles labelled for $\{11 \overline{2} 1\}$ deformation twin interactions across the macrozone. 


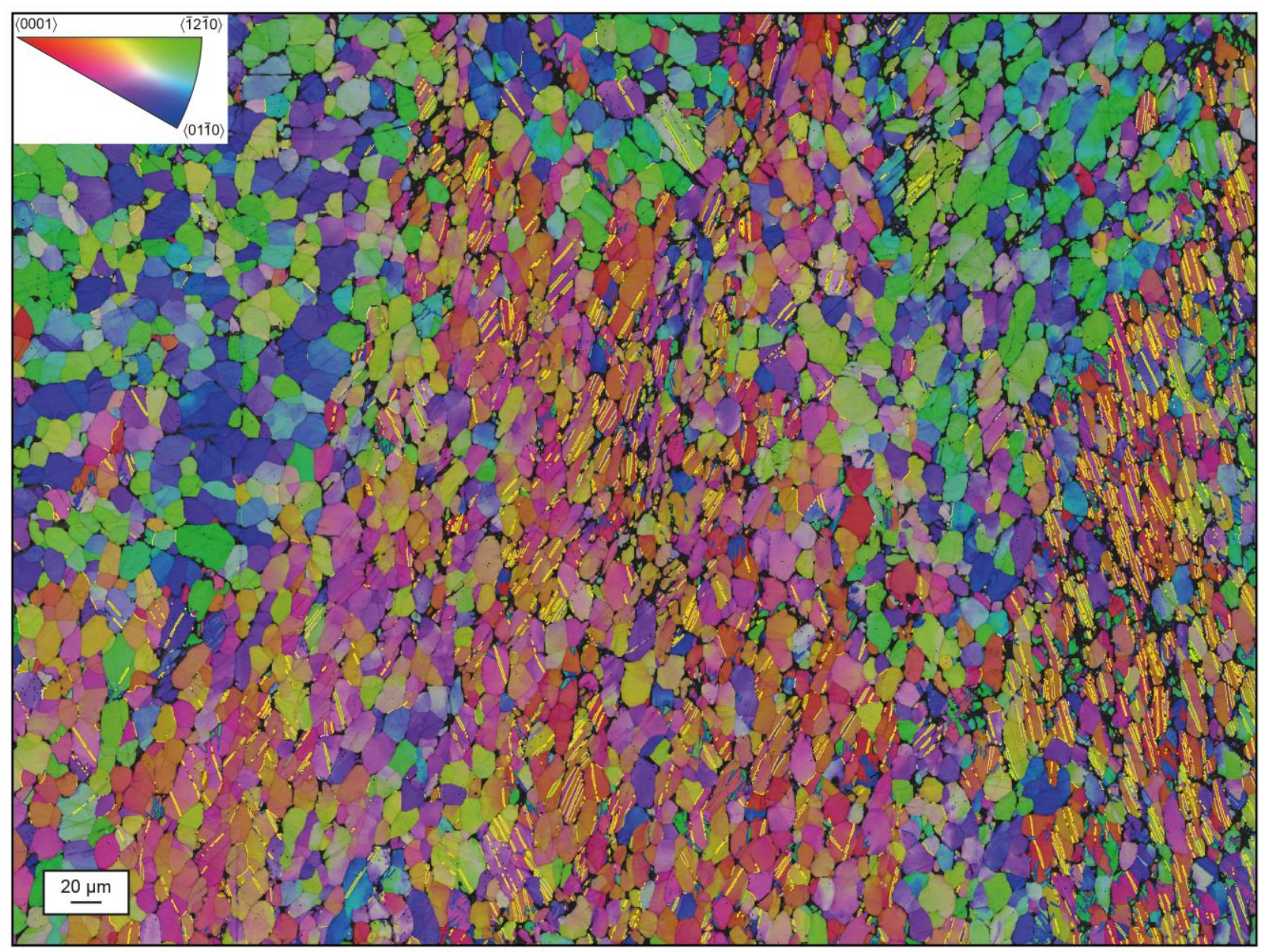

Figure 13. EBSD scan of fine-grained Ti-6Al-4V ballistic sample (Sample F2), $3 \mathrm{~mm}$ away from the impact face at $25 \mathrm{kV}$ with a $0.3 \mu \mathrm{m}$ step size. The loading direction is in the horizontal direction. $z$-direction inverse pole figure colouring with $\{10 \overline{1} 2\}$ deformation twins outlined in blue and $\{11 \overline{2} 1\}$ deformation twins outlined in yellow. $33 \%$ of the deformation twin traces here are indexed as $\{10 \overline{1} 2\}$ and $67 \%$ are indexed as $\{11 \overline{2} 1\}$. 

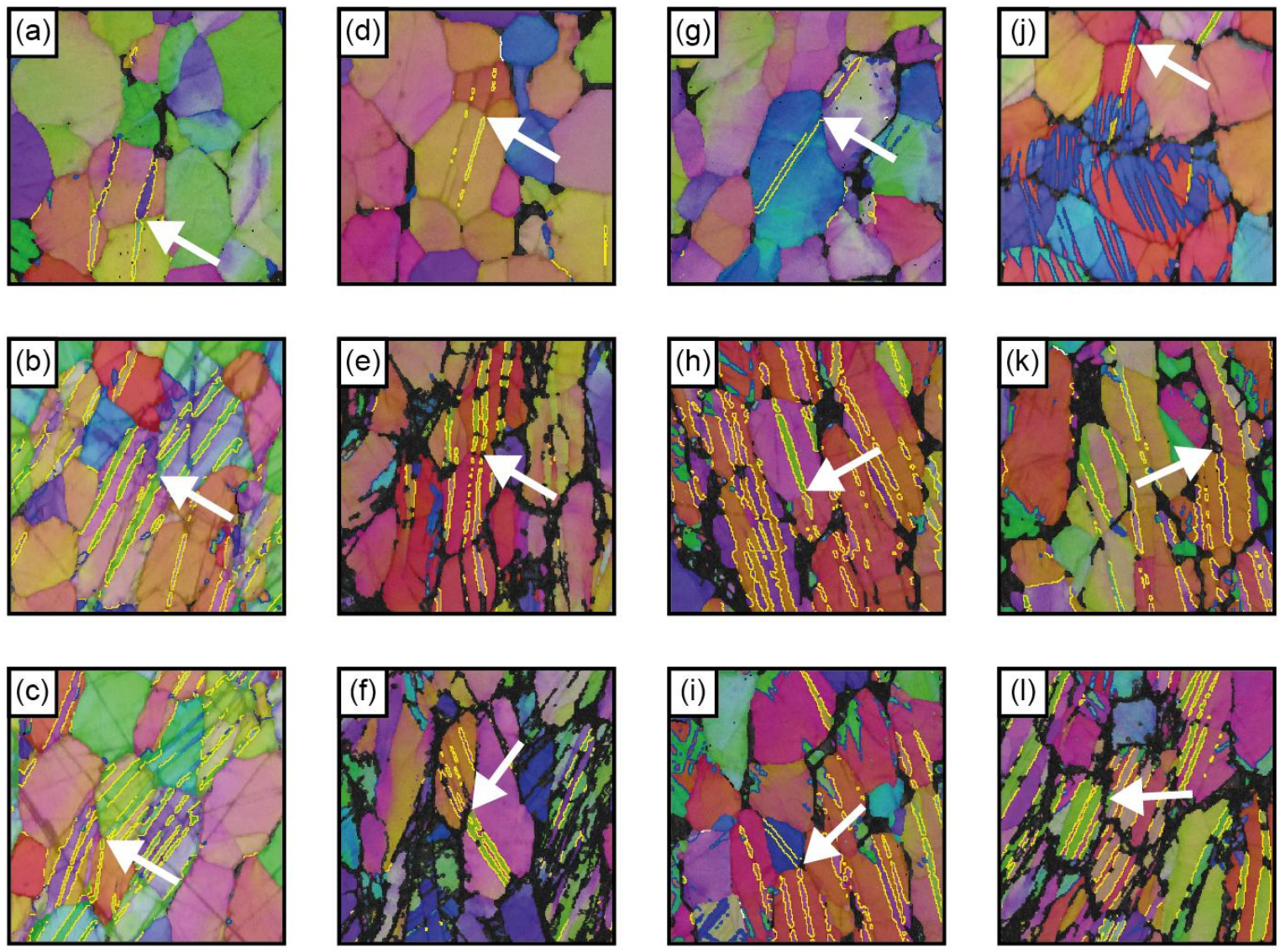

$\langle 0001\rangle$

$\langle\overline{1} 2 \overline{1} 0\rangle$

$10 \mu \mathrm{m}$

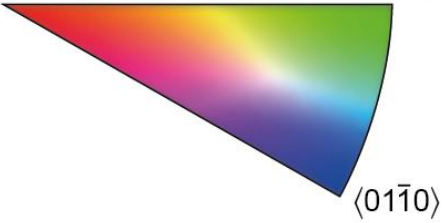

Figure 14. Regions of EBSD scans of fine-grained Ti-6Al-4V ballistic samples that exhibit deformation twinning interactions across various grain boundary angles at $25 \mathrm{kV}$ with a $0.3 \mu \mathrm{m}$ step size. The loading direction is in the horizontal direction. z-direction inverse pole figure colouring with $\{10 \overline{1} 2\}$ deformation twins are outlined in blue and $\{11 \overline{2} 1\}$ deformation twins are outlined in yellow. The grain boundary misorientation measurements of the arrowed interactions are shown in Table 3.

Table 3. Misorientation angle measurements of the grain boundary interactions highlighted in Figure 13.

\begin{tabular}{llllllllllllll} 
Figure 13 & $($ a) & (b) & $($ c) & (d) & (e) & (f) & (g) & (h) & (i) & (j) & (k) & (l) \\
\hline Misorientation & $19^{\circ}$ & $21^{\circ}$ & $45^{\circ}$ & $17^{\circ}$ & $32^{\circ}$ & $20^{\circ}$ & $29^{\circ}$ & $32^{\circ}$ & $65^{\circ}$ & $30^{\circ}$ & $8^{\circ}$ & $55^{\circ}$ \\
\hline
\end{tabular}




\subsubsection{Spurious twin traces}

When analysing the deformation twinning interactions across grain boundaries it became apparent that some of the features attributed to traces of $\{11 \overline{2} 1\}$ twins from their appearance and connectivity with other $\{11 \overline{2} 1\}$ twins had a misorientation relationship that deviated considerably from the ideal misorientation of $34.96^{\circ}$ about [1010] tabulated in [11]. Some examples of this phenomenon are shown in Figure 15.
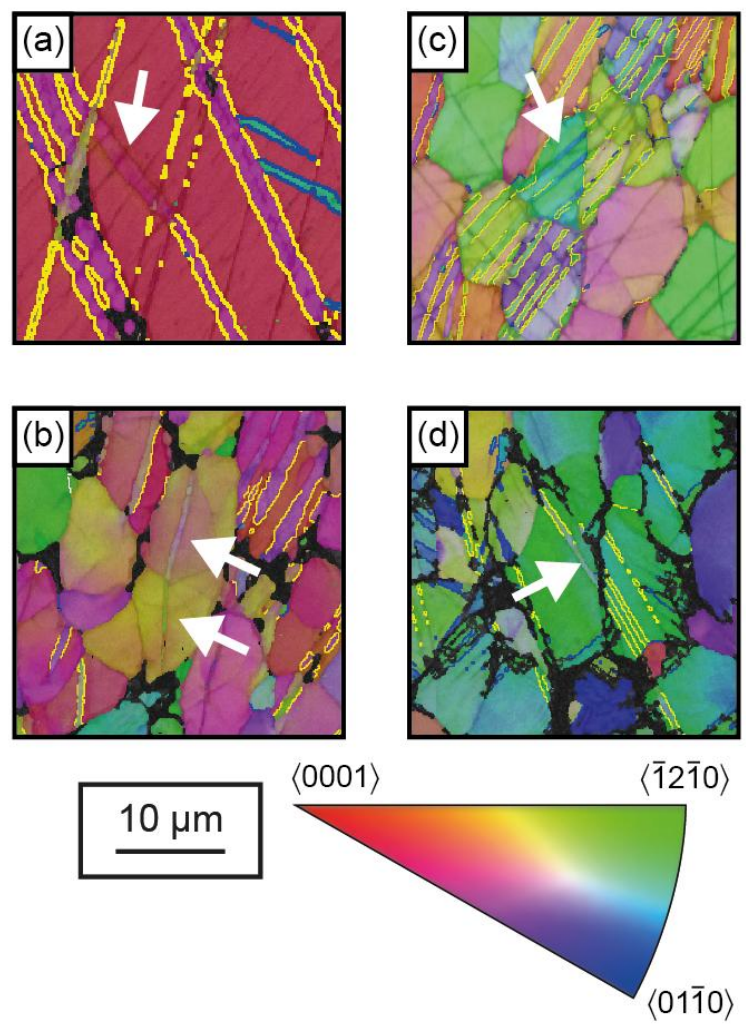

Figure 15. Regions of EBSD scans of fine-grained Ti-6Al-4V ballistic samples that exhibit deformation twinning interactions with twin traces that have a misorientation that deviates considerably from ideal for a $\{11 \overline{2} 1\}$ deformation twin. The scans were acquired at $25 \mathrm{kV}$ with a $0.3 \mu \mathrm{m}$ step size. The loading direction is in the horizontal direction. $z$ direction inverse pole figure colouring, with $\{10 \overline{1} 2\}$ deformation twins outlined in blue and $\{11 \overline{2} 1\}$ deformation twins outlined in yellow. Some examples of deformation twins with a different misorientation than expected are arrowed.

In Figure $15(\mathrm{a})$ one of the $\{11 \overline{2} 1\}$ twin traces that spans between another two $\{11 \overline{2} 1\}$ twin traces has a misorientation relationship that can be measured to be approximately $18^{\circ}$ between the twin and the parent grain. The trace of that section of the $\{11 \overline{2} 1\}$ twin also deviates considerably from alignment with the rest of the yellow indexed $\{11 \overline{2} 1\}$ twin trace. Similarly in Figure 15(c) and 15(d) sections of 
$\{11 \overline{2} 1\}$ twins that have interacted across $\alpha$ phase grain boundaries have similar misorientation angles of $22^{\circ}$ and $18^{\circ}$ respectively. In Figure $15(\mathrm{~b})$ there is an interaction of what appears to be two deformation twins where the misorientation angle is $14^{\circ}$.

\subsubsection{Discussion}

The deformation twin interactions across $\alpha$ lath boundaries and higher angle $\alpha$ lath colony grain boundaries in $\mathrm{Ti}-6 \mathrm{Al}-4 \mathrm{~V}$ support and extend results obtained for grain boundary interactions in $\mathrm{CP}$ titanium [15]. The results presented here from the coarse-grained samples demonstrate $\alpha$ lath insignificance in Ti-6Al-4V at high strain rate. Both $\{10 \overline{1} 2\}$ and $\{11 \overline{2} 1\}$ deformation twins were observed interacting across the low angle $\alpha$ lath boundaries (Figure 10). However, with the higher angle $\alpha$ lath colony boundaries, as shown in Figure 11, only $\{11 \overline{2} 1\}$ deformation twins were observed interacting across the boundaries. This result was also evident in the fine-grained samples, in which the $\alpha$ phase grain boundary interactions were almost exclusively only observed for $\{11 \overline{2} 1\}$ deformation twinning. Other than infrequent examples of $\{10 \overline{1} 2\}-\{11 \overline{2} 1\}$ interactions, all of the $\alpha$ phase grain boundary interactions were between $\{11 \overline{2} 1\}$ deformation twins, as is evident from Figures $12-14$. This finding contrasts with the grain boundary interactions in CP titanium, in which $\{10 \overline{1} 2\}$ as well as other deformation twinning types were observed interacting across $\alpha$ lath boundaries and higher angle $\alpha$ phase grain boundaries [15]. The upper limit of grain misorientation of $23^{\circ}$ in rhenium for twin transmission that was observed recently by Kacher and Minor [25] does not apply to Ti-6Al-4V or CP titanium; in both these studies $\{1121\}$ twinning has been observed interacting across $65^{\circ}$ misorientation grain boundaries.

It is not clear why only $\{11 \overline{2} 1\}$ twins were observed interacting across $\alpha$ lath colony boundaries in $\mathrm{Ti}-6 \mathrm{Al}-4 \mathrm{~V}$. However, the most striking difference between the $\{10 \overline{1} 2\}$ and $\{11 \overline{2} 1\}$ deformation twins that was observed was the morphology of the two deformation twinning types. $\{11 \overline{2} 1\}$ twins have a narrow morphology and tend to span entire grains or multiple grains. By comparison, $\{10 \overline{1} 2\}$ twins have a wider morphology and are usually limited to individual grains. The reason why $\{11 \overline{2} 1\}$ twins span multiple grains is likely to be due to the difference between nucleating a new deformation twin in comparison with either thickening the twin width or propagating the twin length. Other researchers have suggested that there is a lower energy barrier to the thickening of $\{10 \overline{1} 2\}$ deformation twins in titanium in comparison with the energy barrier for nucleating new $\{10 \overline{1} 2\}$ deformation twins $[2,4]$. 
As we have noted in Section 3.1, $\{11 \overline{2} 1\}$ deformation twinning has a shear magnitude which is more than three times higher than the shear magnitude for $\{10 \overline{1} 2\}$ deformation twinning. This may be a contributing factor to the choice of twin. It is possible that at these very high strain rates, the lower $q=$ 2 shuffle complexity for $\{11 \overline{2} 1\}$ deformation twinning enables these twins to be nucleated more readily in neighbouring grains to accommodate plastic deformation than the $\{10 \overline{1} 2\}$ deformation twins, to the extent that the Schmid factor, while clearly important, is not the key factor determining twin selection, as we have already noted in twin selection in individual grains in Section 3.1.

From the EBSD data it is difficult to deduce if the deformation twin traces pass directly through retained $\beta$ phase between the $\alpha$ laths. The $\beta$ phase is not easily indexed in the EBSD scans because this relatively soft phase is preferentially etched and polished during the sample preparation for EBSD analysis. However, with the widespread interaction of both $\{10 \overline{1} 2\}$ and $\{11 \overline{2} 1\}$ deformation twins across $\alpha$ lath boundaries that was observed, it is probable that retained $\beta$ phase between the $\alpha$ laths does not affect the propagation of deformation twinning across $\alpha$ lath colonies. Some evidence of retained $\beta$ phase between $\alpha$ laths was visible at grain boundary interactions, such as in Figure 16. This observation should also be applicable to low angle grain boundaries in equiaxed fine grain Ti-6Al-4V with retained $\beta$ phase between the $\alpha$ phase grains.
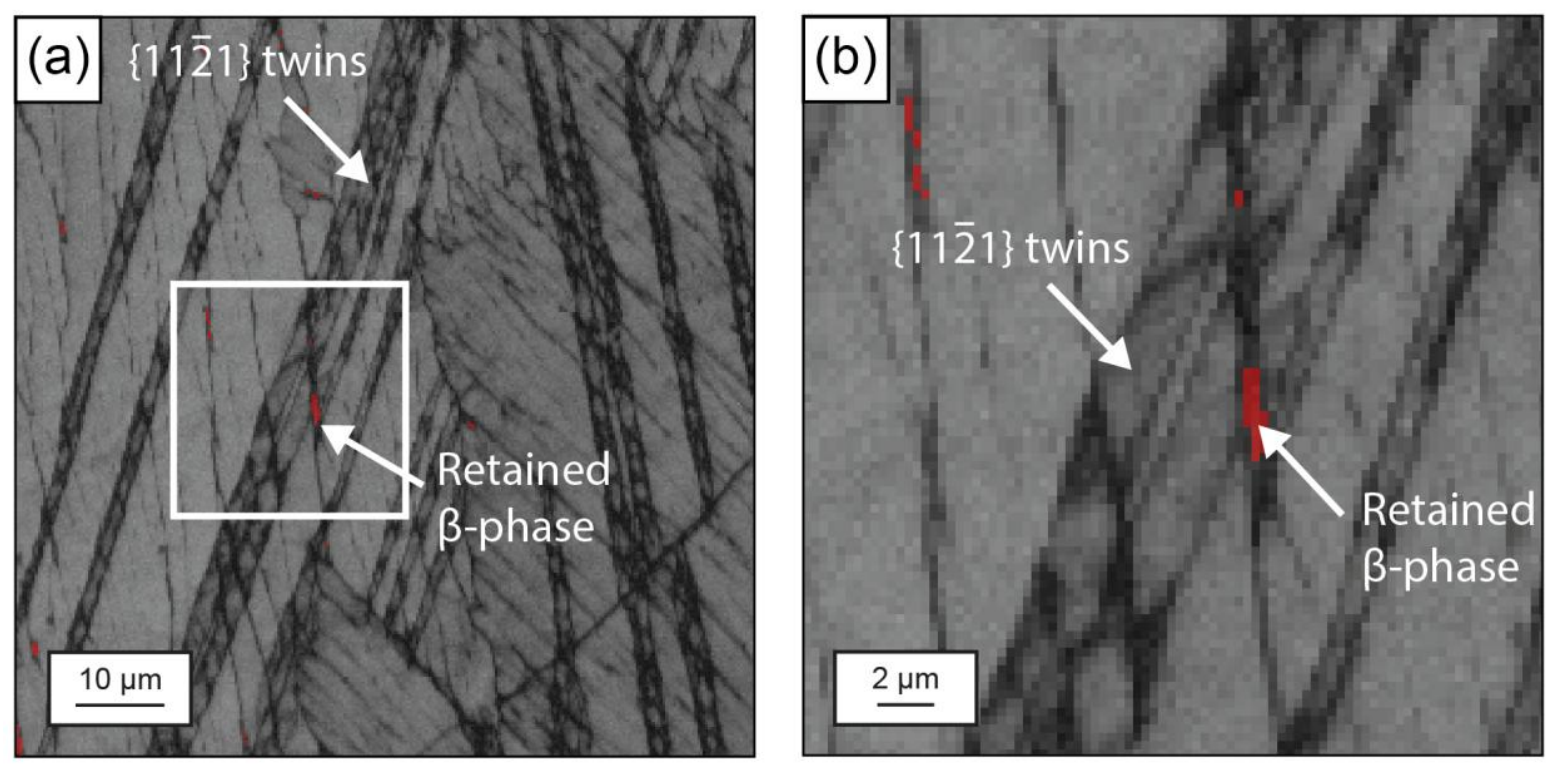

Figure 16. (a) EBSD scan from Figure 10 of coarse-grained Ti-6Al-4V at $25 \mathrm{kV}$ with a $0.3 \mu \mathrm{m}$ step size. The loading direction is in the horizontal direction. The retained $\beta$ phase between $\alpha$ laths is indexed in red. $\{11 \overline{2} 1\}$ deformation twins interact across the $\alpha$ lath boundaries with retained $\beta$ phase. (b) higher magnification of the boxed region in (a). 
Careful FIB extraction and TEM analysis could provide conclusive evidence for retained $\beta$ phase between the $\alpha$ laths. Unfortunately, attempted focused ion beam (FIB) extractions of the twin-twin interactions in these samples were unsuccessful because of the difficulty of retaining the region of interest in a cross-sectional FIB extraction.

The spurious deformation twin traces shown in Figure 15 are very interesting observations. One explanation for the deviation from the expected misorientation relationship is that the parent grain could have undergone considerable grain rotation in the subsequent deformation, sufficient enough to change the orientation relationship between the $\{11 \overline{2} 1\}$ twin and the parent grain. However, this is not a likely explanation, simply because it is not observed elsewhere with other deformation twins. The association between the spurious orientation relationship and $\{11 \overline{2} 1\}$ deformation twin traces that interact across one or multiple grain boundaries is likely to be significant. While challenging, FIB extraction of such spurious twin traces in ballistically deformed $\mathrm{Ti}-6 \mathrm{Al}-4 \mathrm{~V}$ would enable the misorientation to be characterised in detail in the TEM.

\subsection{Whole grain twinning in Ti-6Al-4V}

As discussed in Section 1, Prakash et al. have suggested that whole grains of Ti-6Al-4V are able to twin by the $\{10 \overline{1} 2\}$ deformation twinning mode [2]. Observations such as those in Figures 17 and 18 on both the coarse and fine-grained ballistically deformed Ti-6Al-4V samples show that $\{10 \overline{1} 2\}$ deformations twins can reorient large fractions of individual grains, with some evidence of almost entirely reoriented grains. 


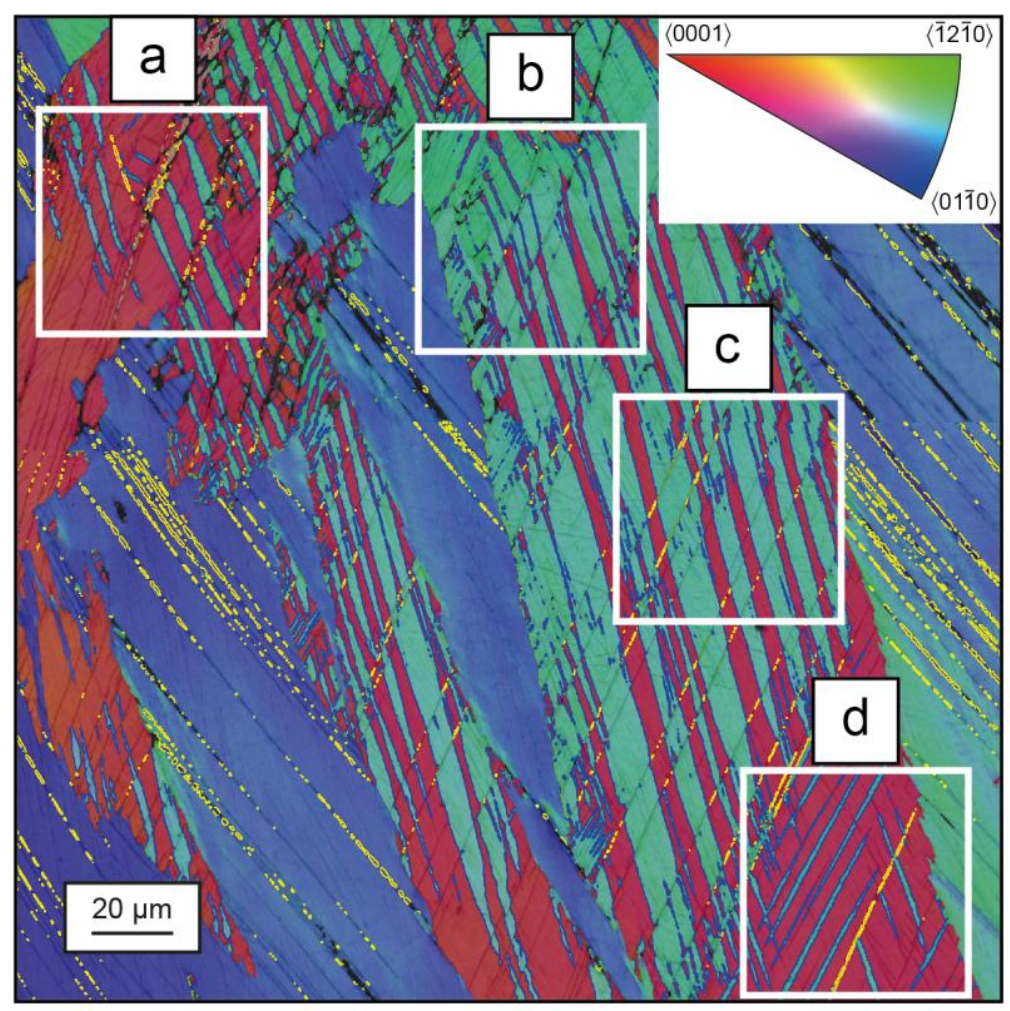

Figure 17. EBSD scan of coarse-grained Ti-6Al-4V ballistic sample at $25 \mathrm{kV}$ with a $0.3 \mu \mathrm{m}$ step size. The loading direction is in the horizontal direction. $z$-direction inverse pole figure colouring with $\{10 \overline{1} 2\}$ deformation twins are outlined in blue and $\{11 \overline{2} 1\}$ deformation twins are outlined in yellow. In regions (a) and (d) the twinned material is a relatively low volume fraction relative to the original parent grains, whereas in regions (b) and (c) there is a higher volume fraction of the $\{10 \overline{1} 2\}$ twinned orientation than the original parent grain orientation.

The highlighted regions (a) to (d) of Figure 17 show how the $\{10 \overline{1} 2\}$ deformation twins have almost entirely reoriented the parent grain orientation to a $\{10 \overline{1} 2\}$ twinned orientation. In regions (a) and (d) it is clear that the turquoise coloured regions are the twinned material and the red region is the parent grain. However, if regions (b) and (c) in Figure 17 are considered in isolation without the knowledge of the rest of the scan, it is impossible to specify with confidence which orientation belongs to the parent grain, and which orientation is twinned material. In regions (b) and (c) of Figure 17 there is actually a higher volume fraction of the twinned orientation than the original parent grain orientation. Examples of partially reoriented grains in the fine-grained $\mathrm{Ti}-6 \mathrm{Al}-4 \mathrm{~V}$ are shown in Figure 18. 

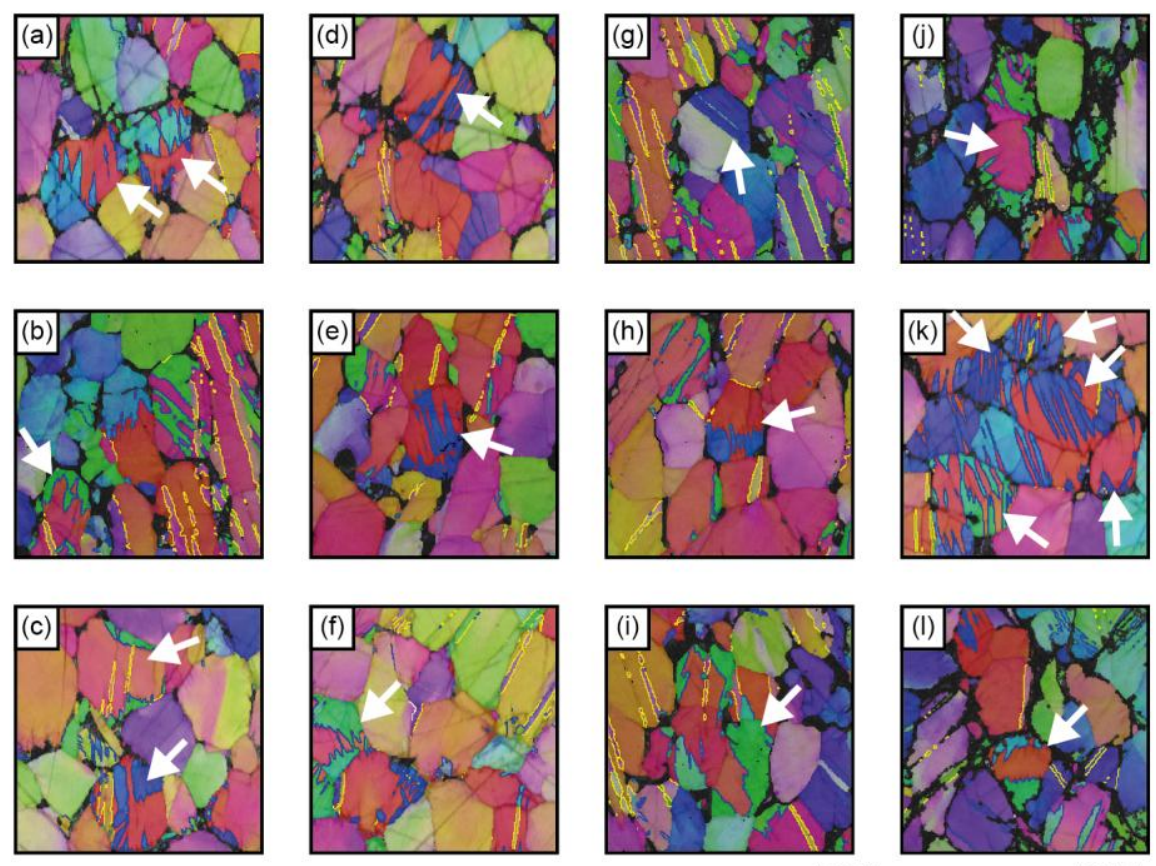

$10 \mu \mathrm{m}$
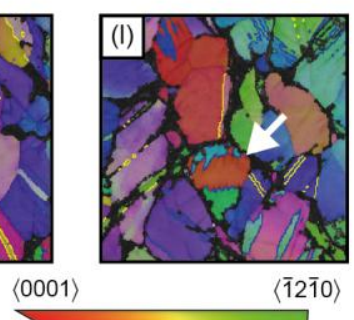

$\langle 0001\rangle$

$\langle\overline{1} 2 \overline{1} 0\rangle$

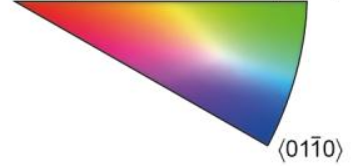

Figure 18. Regions of EBSD scans of fine-grained Ti-6Al-4V ballistic samples that exhibit grains that have partially reoriented by deformation twinning. The partially reoriented grains are highlighted. The scans were acquired at $25 \mathrm{kV}$ with a $0.3 \mu \mathrm{m}$ step size. The loading direction is in the horizontal direction. $z$-direction inverse pole figure colouring with $\{10 \overline{1} 2\}$ deformation twins are outlined in blue and $\{11 \overline{2} 1\}$ deformation twins are outlined in yellow. Some examples of partial orientation are arrowed.

These results therefore show some evidence for almost whole grain twinning in Ti-6Al-4V. Previous results by Preuss et al. [2,4], while compelling, did not have evidence of grains that were partially or nearly entirely reoriented, presumably because the strain rates of $10^{-6} \mathrm{~s}^{-1}$ at which these observations were made was sufficiently slow that whole grains had time to reorient completely. The results presented here at ballistic strain rates clearly show grains that are partially, but significantly, reoriented. In Figure $18(\mathrm{~g})$ the middle grain has a $\{10 \overline{1} 2\}$ twin trace through the middle of it, which suggests that half of the grain has been reoriented to a twinned orientation. The evidence for whole grain twinning presented in Figures 17 and 18 is consistently the consequence of thickened or joined up $\{10 \overline{1} 2\}$ deformation twins. As discussed in Section 3.2.4, the suggestion by Preuss et al. [2,4] that $\{10 \overline{1} 2\}$ deformation twins require less energy to thicken than to propagate would seem to be a plausible explanation. This also explains qualitatively why the finding is limited to $\{10 \overline{1} 2\}$ 
deformation twinning, because $\{10 \overline{1} 2\}$ deformation twinning has the lowest twinning shear of all of the deformation twinning types observed in titanium. For conclusive proof of whole grain twinning as a plastic deformation mechanism, it would be necessary to characterise in situ the orientation of a grain before, during and after deformation.

\section{Conclusions}

Observations of Ti-6Al-4V deformed at very high strain rates at room temperature confirm prior studies which have shown evidence for only $\{10 \overline{1} 2\}$ and $\{11 \overline{2} 1\}$ tension deformation twins being able to operate. Significantly, there was no evidence for compression deformation twins which are able to operate in $\mathrm{CP}$ titanium in those $\mathrm{Ti}-6 \mathrm{Al}-4 \mathrm{~V}$ grains whose $c$-axis was within $10^{\circ}$ of the compression axis of the cylindrical projectiles used in the Taylor impact tests. Deformation twinning is able to propagate through h.c.p. $\alpha$ lath boundaries and higher angle $\alpha$ grain boundaries in Ti-6Al-4V despite having thin sub- $\mu$ m layers of retained b.c.c. $\beta$ phase at these boundaries, but whereas both $\{10 \overline{1} 2\}$ and $\{11 \overline{2} 1\}$ deformation twins can be transmitted across low angle grain ( $\alpha$ lath) boundaries, only $\{11 \overline{2} 1\}$ deformation twins can be transmitted across higher angle grain boundaries. The morphologies of the $\{10 \overline{1} 2\}$ and $\{11 \overline{2} 1\}$ deformation twins were also noticeably different - the $\{10 \overline{1} 2\}$ deformation twins were the more thin, while the wider $\{10 \overline{1} 2\}$ deformation twins were usually limited to individual grains, reorienting almost entire grains to a twinned orientation.

\section{Acknowledgements}

This work was supported by the Rolls-Royce plc/EPSRC strategic partnership under EP/H022309/1. The authors are grateful to Drs Andrew P. Jardine and Stephen M. Walley from the Surfaces, Microstructure and Fracture group of the Cavendish Laboratory, Cambridge for help with the ballistic testing. Requests for access to the underlying research data should be directed to the corresponding authors and will be considered against commercial interests and data protection.

\section{Declaration of interest statement}

The authors declare that they have no known competing financial interests or personal relationships that could have appeared to influence the work reported in this paper. 


\section{Appendix A - Crystallographic analysis of the $\alpha$ phase grains in Figure 11}

The purpose of this Appendix is to examine the proposition that prior to the ballistic testing, the various $\alpha$ h.c.p. grains evident in Figure 11 were all derived from a single prior $\beta$ b.c.c. grain. For convenience, Figure 11(a) is reproduced here as Fig. A.1, with the five different grains clearly visible in the figure labelled $1-5$. Grains $1-4$ all contain $\{11 \overline{2} 1\}$ twins as a consequence of the ballistic testing; grain 5 is free from such twinning.

Our analysis follows the methodology described by Gey and Humbert [26] and Karthikeyan et al. [27]. In both of these studi7es the Burgers orientation relationship between the $\alpha$ h.c.p. phase and the $\beta$ b.c.c. phase is assumed, in which the (0001) close-packed plane of the $\alpha$ h.c.p. phase is parallel to a $\{110\}$ plane of the $\beta$ b.c.c. phase, and where in addition close-packed directions within these two planes are also parallel [28], such as the variant for which

$$
(0001)_{\alpha} \|(110)_{\beta} \text { and }[11 \overline{2} 0]_{\alpha} \|(\overline{1} 1 \overline{1})_{\beta}
$$

As Gey and Humbert [26] and Karthikeyan et al. [27] describe, there are twelve $\alpha$ variants which can be generated from a single prior $\beta$ grain. For each variant, there are 12 possible ways in which the $\mathbf{a}_{\mathrm{H}}, \mathbf{b}_{\mathrm{H}}$ and $\mathbf{c}_{\mathrm{H}}$ basis vectors of the hexagonal unit cell can be defined with respect to the basis vectors $\mathbf{i}_{\beta}, \mathbf{j}_{\beta}$ and $\mathbf{k}_{\beta}$ of the $\beta$ phase body-centred cubic unit cell, where the subscript ' $\mathrm{H}$ ' here denotes hexagonal. In addition, the $\alpha$ variants originating from a common $\beta$ grain will have specific misorientations between themselves. These are best described in terms of the rotation with the lowest angle possible, i.e. the disorientation in the language used by Grimmer for rotations between cubic lattices [29]. Data for these possible disorientations for the Burgers orientation relationship are given in Table A.1. These data are based on Table 1 of Gey and Humbert [26] and Table 1 of Karthikeyan et al. [27]; these are equivalent descriptions once it is appreciated that there is a minor numerical error in [1]: $72.73^{\circ}$ in their Table 1 should be $72.43^{\circ}$.

In practice of course, for an actual sample, such as the cold-rolled and annealed commercially pure titanium T40 sample studied by Gey and Humbert, there will be angular deviations between the experimentally determined disorientations and the theoretical disorientations. Acceptable angular deviations characteristic of adjacent $\alpha$ grains arising from the same 'parent' $\beta$ grain can be characterised in terms of allowed tolerance angles $\tau$ of the rotation matrix specifying the mismatch between the experimentally determined disorientation and the theoretical disorientation. Gey and Humbert suggested a value of $5^{\circ}$ as being an acceptable angular deviation and show examples where $\beta$ parent grains can be identified from cold-rolled and annealed material. 


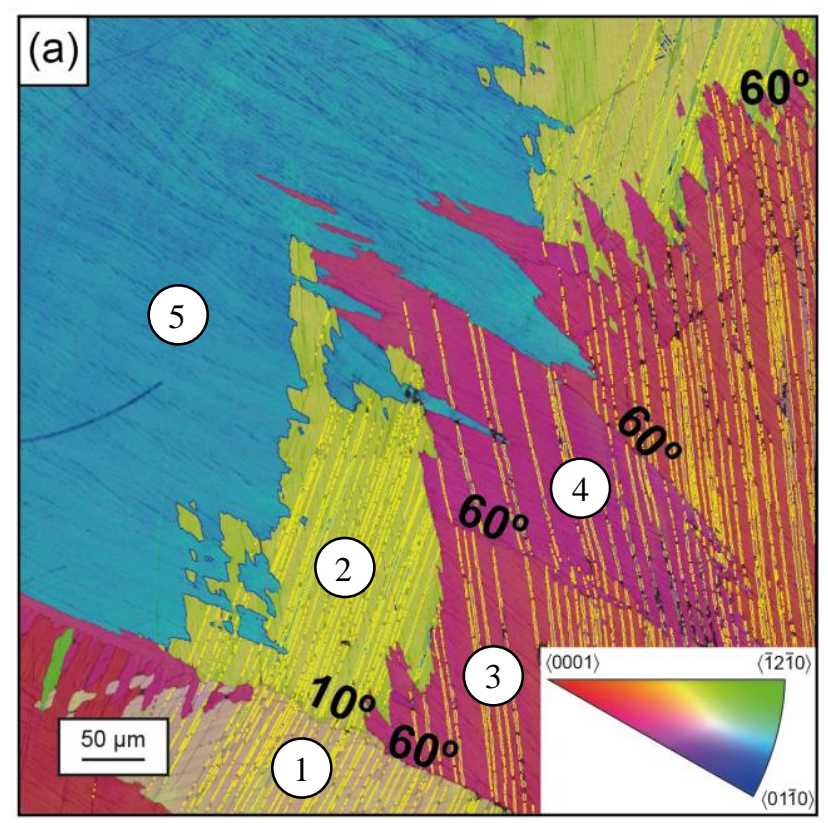

Figure A.1. $z$-direction inverse pole figure colouring and band contrast from a ballistic sample of coarse-grained Ti$6 \mathrm{Al}-4 \mathrm{~V} 3 \mathrm{~mm}$ away from the impact face with $\{11 \overline{2} 1\}$ deformation twins outlined in yellow and the grain boundary misorientation angles labelled to one significant figure. Grains 1-5 of h.c.p. $\alpha$ considered in this Appendix are indicated.

Table A.1. Disorientation angle-axis descriptions for $\alpha$ h.c.p. variants inherited from the same b.c.c $\beta$ grain where the orientation relationship between $\alpha$ and $\beta$ is the Burgers orientation relationship. (After Table 1 of [26] and Table 1 of [27].)

\begin{tabular}{ccc}
\hline Disorientation Type & Disorientation angle $\left({ }^{\circ}\right)$ & H.c.p. disorientation axis \\
\hline I & 10.529 & $\mathbf{c}=[0001]$ \\
II & 60 & $\mathbf{a}=\langle 11 \overline{2} 0\rangle$ \\
III & 60.832 & In $(\mathbf{n}, \mathbf{c})$ plane, $9.03^{\circ}$ from $\mathbf{~}$ \\
IV & 63.262 & In $(\mathbf{a}, \mathbf{c})$ plane, $17.56^{\circ}$ from $\mathbf{a}$ \\
V & 90 & $\mathbf{n}$ in basal plane $5.26^{\circ}$ from $\langle 11 \overline{2} 0\rangle$ \\
\hline
\end{tabular}

The procedure used to examine the crystallography of Figure A.1 was as follows. Raw Euler angles determined by the EBSD software to the nearest degree using the Bunge convention shown in Table A. 2 were first converted for grains 1 and 2 to the reduced angular space $\phi_{1}:[0,2 \pi], \Phi:[0, \pi / 2]$, $\phi_{2}:[0, \pi / 3]$ using the methodology described by Karthikeyan et al. [27] which recognises the six-fold and two-fold rotational symmetry elements present in hexagonal materials. The raw data for grain 5 was already within this reduced angular space, but to be able to specify disorientation descriptions between grain 1 and grains 3 and 4 , the angular constraint on $\phi_{2}:[0, \pi / 3]$ had to be relaxed to $\phi_{2}:[-\pi, \pi]$. 
Table A.2. Raw Euler angle data for grains 1-5 shown in Figure A.1.

\begin{tabular}{cccc}
\hline Grain & $\phi_{1}\left({ }^{\circ}\right)$ & $\Phi\left(^{\circ}\right)$ & $\phi_{2}\left(^{\circ}\right)$ \\
\hline 1 & 149 & 127 & 13 \\
2 & 150 & 130 & 5 \\
3 & 61 & 25 & 32 \\
4 & 56 & 149 & 29 \\
5 & 61 & 89 & 17 \\
\hline
\end{tabular}

These sets of Euler angles $\left(\phi_{1 i}, \Phi_{l} \phi_{2 i}\right)$ for $i=1,5$ then enable rotation matrices $\mathbf{R}_{i}$ for $i=1,5$ to be defined [30-32] so that a set of orthornormal basis vectors $\mathbf{i}, \mathbf{j}$ and $\mathbf{k}$ defined with respect to a reference frame in the scanning electron microscope, where the vector $\mathbf{k}$ is parallel to the normal to the surface under examination, rotate to a set of orthonormal basis vectors $\mathbf{i}_{\mathrm{G} i}, \mathbf{j}_{\mathrm{G} i}$ and $\mathbf{k}_{\mathrm{G} i}$ for $i=$ 1,5 defined with respect to each of the five grains through equations of the form

$$
\left(\begin{array}{c}
\mathbf{i}_{\mathrm{G} i} \\
\mathbf{j}_{\mathrm{G} i} \\
\mathbf{k}_{\mathrm{G} i}
\end{array}\right)=\mathbf{R}_{\varphi_{2 i}} \mathbf{R}_{\Phi_{i}} \mathbf{R}_{\varphi_{1 i}}\left(\begin{array}{c}
\mathbf{i} \\
\mathbf{j} \\
\mathbf{k}
\end{array}\right)=\mathbf{R}_{i}\left(\begin{array}{c}
\mathbf{i} \\
\mathbf{j} \\
\mathbf{k}
\end{array}\right)
$$

where each of the set of orthonormal vectors defining the grains is oriented so that $\mathbf{k}_{\mathrm{G} i}$ is parallel to the $\mathbf{c}_{\mathrm{H}}$ basis vector, $\mathbf{j}_{\mathrm{G} i}$ is parallel to the $\mathbf{b}_{\mathrm{H}}$ basis vector, or one related to it by symmetry, and $\mathbf{i}_{\mathrm{G} i}$ is parallel to the vector product $\mathbf{j}_{\mathrm{G} i} \times \mathbf{k}_{\mathrm{G} i}$.

If, in fact, each of the five $\alpha$ grains in Fig. A.1 were not derived from a common $\beta$ grain, examination of the disorientations between these variants would establish quickly whether this were true. This is because it would be clearly evident that the experimentally determined disorientation angles and axes are far away from the data for these disorientations given in Table 1 of Gey and Humbert [26] and Table 1 of Karthikeyan et al. [27]. As Karthikeyan et al. show, this is because the relative misorientation between the $\alpha$ variants from a common $\beta$ grain is independent of the $\beta$ orientation itself.

A preliminary analysis of the 10 pairs of disorientations between the five grains showed that in each case there was a disorientation description close to a theoretical disorientation description shown in Table A.1. Most notably, the disorientation between grains 1 and 2 could readily be identified as one where the disorientation description was close to $\pm 10.529^{\circ}$ about a common $\mathbf{k}_{\mathrm{G} 1}\left\|\mathbf{k}_{\mathrm{G} 2}\right\|[0001]_{\mathrm{H}}$ axis.

Choosing the orientation of grain 1 so that 


$$
\left(\begin{array}{l}
\mathbf{i}_{\mathrm{G} 1} \\
\mathbf{j}_{\mathrm{G} 1} \\
\mathbf{k}_{\mathrm{G} 1}
\end{array}\right)=\left(\begin{array}{ccc}
\frac{1}{\sqrt{6}} & -\frac{1}{\sqrt{6}} & -\frac{2}{\sqrt{6}} \\
-\frac{1}{\sqrt{3}} & \frac{1}{\sqrt{3}} & -\frac{1}{\sqrt{3}} \\
\frac{1}{\sqrt{2}} & \frac{1}{\sqrt{2}} & 0
\end{array}\right)\left(\begin{array}{l}
\mathbf{i}_{\beta} \\
\mathbf{j}_{\beta} \\
\mathbf{k}_{\beta}
\end{array}\right)=\mathbf{R}_{1}\left(\begin{array}{l}
\mathbf{i}_{\beta} \\
\mathbf{j}_{\beta} \\
\mathbf{k}_{\beta}
\end{array}\right)
$$

enables the components $[U V W]_{\mathrm{G} 1}$ of a vector $\mathbf{r}$ specified with respect to grain 1 to be related by a Burgers orientation relationship to the components $[u v w]_{\beta}$ of the same vector $\mathbf{r}$ with respect to the prior $\beta$ grain through the equation

$$
\left(\begin{array}{c}
u \\
v \\
w
\end{array}\right)_{\beta}=\left(\begin{array}{ccc}
\frac{1}{\sqrt{6}} & -\frac{1}{\sqrt{3}} & \frac{1}{\sqrt{2}} \\
-\frac{1}{\sqrt{6}} & \frac{1}{\sqrt{3}} & \frac{1}{\sqrt{2}} \\
-\frac{2}{\sqrt{6}} & -\frac{1}{\sqrt{3}} & 0
\end{array}\right)\left(\begin{array}{l}
U \\
V \\
W
\end{array}\right)_{\mathrm{G} 1}=\tilde{\mathbf{R}}_{1}\left(\begin{array}{c}
U \\
V \\
W
\end{array}\right)_{\mathrm{G} 1}
$$

using equations in Appendix 4 of [32]. Eq. (A.3) can be written in the more succinct form:

$$
\mathbf{r}_{\beta}=\tilde{\mathbf{R}}_{1} \mathbf{r}_{\mathrm{G} 1}
$$

Likewise, for grain 2, a similar equation can be written to describe the relationship between the components $[U V W]_{\mathrm{G} 2}$ of a vector $\mathbf{r}$ specified with respect to grain 2 and the components $[u v w]_{\beta}$ of the same vector $\mathbf{r}$ with respect to the prior $\beta$ grain:

$$
\mathbf{r}_{\beta}=\tilde{\mathbf{R}}_{2} \mathbf{r}_{\mathrm{G} 2}
$$

Hence,

$$
\mathbf{r}_{\mathrm{G} 2}=\mathbf{R}_{2} \mathbf{r}_{\beta}=\mathbf{R}_{2} \tilde{\mathbf{R}}_{1} \mathbf{r}_{\mathrm{G} 1}
$$

It is evident that the orientation of grain 2 is such that $\mathbf{k}_{\mathrm{G} 1}\left\|\mathbf{k}_{\mathrm{G} 2}\right\|[110]_{\beta}$; however, there are six equivalent orientations describing the Burgers orientation relationship consistent with this constraint; these are related to one another by the six-fold rotational symmetry about $\mathbf{k}_{\mathrm{G} 2}$. One of these is the one for which the rotation matrix

$$
\mathbf{R}=\mathbf{R}_{2} \tilde{\mathbf{R}}_{1}
$$

gives the disorientation description, i.e. the one with the lowest rotation angle of the symmetrically equivalent descriptions. If the experimental disorientation description, $\mathbf{R}=\mathbf{R}_{\mathrm{exp}}$, is compared with the closest theoretical disorientation description, $\mathbf{R}=\mathbf{R}_{\mathrm{dis}}$, then the magnitude of the tolerance angle $\tau$ of the rotation matrix specifying the mismatch between $\mathbf{R}_{\text {exp }}$ and $\mathbf{R}_{\text {dis }}$ can be determined by 
examining either $\mathbf{R}_{\text {exp }} \tilde{\mathbf{R}}_{\text {dis }}$ or $\mathbf{R}_{\text {dis }} \tilde{\mathbf{R}}_{\text {exp }}$ [30-32]. This principle was applied in turn to each of the 10 pairs of disorientations between the five grains shown in Figure 11. The results of these calculations are shown in Table A.3. Note that, for grain 5, different equivalent Euler angle descriptions from that used to describe the observed disorientation relationships between it and grains 1 have to be used when determining the observed disorientation relationships between it and grains 3 and 4 .

Table A.3. Comparison of experimental disorientation angle-axis data for $\alpha$ h.c.p. grains 1-5 with the closest theoretical disorientation description for $\alpha$ h.c.p. variants inherited from the same b.c.c $\beta$ grain. In this table, the disorientation axis of rotation for each $\alpha$ grain pair is expressed with respect to an orthonormal basis described in the text where $\mathbf{k}_{\mathrm{G} i}$ is parallel to the $\mathbf{c}_{\mathrm{H}}$ basis vector, $\mathbf{j}_{\mathrm{G} i}$ is parallel to the $\mathbf{b}_{\mathrm{H}}$ basis vector, or one related to it by symmetry, and $\mathbf{i}_{\mathrm{G} i}$ is parallel to the vector product $\mathbf{j}_{\mathrm{G} i} \times \mathbf{k}_{\mathrm{G} i}$.

\begin{tabular}{|c|c|c|c|c|c|}
\hline Pair no. & $\begin{array}{l}\alpha \text { grain } \\
\text { pairs }\end{array}$ & $\begin{array}{l}\text { Reduced Euler angles } \\
\qquad \phi_{1} \Phi, \phi_{2}\left(^{\circ}\right)\end{array}$ & $\begin{array}{l}\text { Observed disorientation angle } \\
\text { and axis }\end{array}$ & $\begin{array}{l}\text { Theoretical } \\
\text { disorientation } \\
\text { type }\end{array}$ & $\begin{array}{c}\text { Tolerance } \\
\text { angle, } \tau \text {, from } \\
\mathbf{R}_{\text {exp }} \tilde{\mathbf{R}}_{\text {dis }}\end{array}$ \\
\hline 1 & $\begin{array}{l}1 \\
2\end{array}$ & $\begin{array}{l}329,53,47 \\
330,50,55\end{array}$ & $\begin{array}{c}9.16^{\circ} ; \\
{[-0.140,0.309,0.941]}\end{array}$ & I & $3.6^{\circ}$ \\
\hline 2 & $\begin{array}{l}1 \\
3\end{array}$ & $\begin{array}{l}329,53,47 \\
61,25,-28\end{array}$ & $\begin{array}{c}57.90^{\circ} ; \\
{[-0.188,0.980,0.069]}\end{array}$ & III & $8.0^{\circ}$ \\
\hline 3 & $\begin{array}{l}1 \\
4\end{array}$ & $\begin{array}{l}329,53,47 \\
236,31,151\end{array}$ & $\begin{array}{c}65.55^{\circ} ; \\
{[-0.847,0.380,0.371]}\end{array}$ & IV & $7.7^{\circ}$ \\
\hline 4 & $\begin{array}{l}1 \\
5\end{array}$ & $\begin{array}{l}329,53,47 \\
61,89,17\end{array}$ & $\begin{array}{c}91.34^{\circ} \\
{[0.758,0.647,0.077]}\end{array}$ & V & $9.8^{\circ}$ \\
\hline 5 & $\begin{array}{l}2 \\
3\end{array}$ & $\begin{array}{l}330,50,55 \\
61,25,-28\end{array}$ & $\begin{array}{c}54.89^{\circ} \\
{[-0.100,0.993,-0.064]}\end{array}$ & II & $8.3^{\circ}$ \\
\hline 6 & $\begin{array}{l}2 \\
4\end{array}$ & $\begin{array}{l}330,50,55 \\
236,31,151\end{array}$ & $\begin{array}{c}60.61^{\circ} ; \\
{[-0.867,0.429,0.253]}\end{array}$ & IV & $5.4^{\circ}$ \\
\hline 7 & $\begin{array}{l}2 \\
5\end{array}$ & $\begin{array}{l}330,50,55 \\
61,89,17\end{array}$ & $\begin{array}{c}90.17^{\circ} ; \\
{[0.822,0.569,0.030]}\end{array}$ & V & $2.5^{\circ}$ \\
\hline 8 & $\begin{array}{l}3 \\
4\end{array}$ & $\begin{array}{c}61,25,-28 \\
236,31,151\end{array}$ & $\begin{array}{c}56.31^{\circ} ; \\
{[-0.876,-0.470,-0.109]}\end{array}$ & III & 6.3 \\
\hline 9 & $\begin{array}{l}3 \\
5\end{array}$ & $\begin{array}{l}61,25,-28 \\
61,89,317\end{array}$ & $\begin{array}{c}65.55^{\circ} ; \\
{[0.797,0.568,-0.204]}\end{array}$ & IV & 8.7 \\
\hline 10 & $\begin{array}{l}4 \\
5\end{array}$ & $\begin{array}{l}236,31,151 \\
241,91,263\end{array}$ & $\begin{array}{c}61.76^{\circ} ; \\
{[-0.867,-0.449,0.217]}\end{array}$ & III & 4.5 \\
\hline
\end{tabular}


Inspection of the data in Table A.3 shows that for each of the ten possible pairs of grains, each pair has a disorientation description within $10^{\circ}$ of a theoretical disorientation type. For three of these pairs, the tolerance angle is within the $5^{\circ}$ tolerance angle suggested by Gey and Humbert from their analysis of material which had been cold rolled and $\beta$ treated, but not subsequently plastically deformed [26]. Given that the EBSD data was obtained $3 \mathrm{~mm}$ away from the impact face of a sample which had been ballistically deformed, it seems entirely reasonable to set a tolerance angle larger than $5^{\circ}$ when judging whether or not the five $\alpha$ h.c.p. grains in Figure A.1 emanate from a common $\beta$ grain. Confirmation of inherent variability in the experimental determination of the Euler angles can be seen in subtle colour changes in Figure A.1 of grain 3 in particular from one region to another and in the corresponding Euler angle descriptions from place to place within grain 3. Therefore, on the basis of this analysis, we conclude that it is highly likely that these five $\alpha$ h.c.p. grains all derive from a common $\beta$ grain.

\section{References}

[1] M. Zhang, F. Bridier, P. Villechaise, J. Mendez, D.L. McDowell, Simulation of slip band evolution in duplex Ti-6Al-4V, Acta Mater. 58 (2010) 1087-1096.

[2] M. Preuss, J.Q. da Fonseca, V. Allen, D.G.L. Prakash, M.R. Daymond, Twinning in structural material with a hexagonal close-packed crystal structure, J. Strain Anal. Eng. Des. 45 (2010) 377-390.

[3] W. Tirry, F. Coghe, S. Bouvier, M. Gasperini, L. Rabet, D. Schryvers, A multi-scale characterization of deformation twins in Ti6Al4V sheet material deformed by simple shear, Mater. Sci. Eng. A. 527 (2010) 4136-4145.

[4] D.G.L. Prakash, R. Ding, R.J. Moat, I. Jones, P.J. Withers, J.Q. Da Fonseca, M. Preuss, Deformation twinning in Ti-6Al-4V during low strain rate deformation to moderate strains at room temperature, Mater. Sci. Eng. A. 527 (2010) 5734-5744.

[5] F. Coghe, W. Tirry, L. Rabet, D. Schryvers, P. Van Houtte, Importance of twinning in static and dynamic compression of a $\mathrm{Ti}-6 \mathrm{Al}-4 \mathrm{~V}$ titanium alloy with an equiaxed microstructure, Mater. Sci. Eng. A. 537 (2012) 1-10.

[6] G.G. Yapici, I. Karaman, Z.-P. Luo, Mechanical twinning and texture evolution in severely deformed Ti-6Al-4V at high temperatures, Acta Mater. 54 (2006) 3755-3771. 
[7] G.T. Gray, Deformation twinning: influence of strain rate, in Twinning in Advanced Materials, ed. M.H. Yoo, M. Wuttig (1993) pp. 337-349. Warrendale, PA: Min. Met. Mater. Soc. (TMS).

[8] G.T. Gray, V. Livescu, R.A. Beal, E.K. Cerreta, B.M. Morrow, K.S. Vecchio, The shear response of high-purity Ti and Ti-6Al-4V as a function of texture, in: Proc. 13th World Conf. Titanium, 2016, ed. V. Venkatash, A.L. Pilchak and J.E. Allison, Wiley-TMS, San Diego: pp. $645-650$.

[9] G.T. Gray, High-strain-rate deformation: mechanical behavior and deformation substructures induced, Ann. Rev. Mater. Res. 42 (2012) 285-303.

[10] E. Wielewski, C.R. Siviour, N. Petrinic, On the correlation between macrozones and twinning in Ti-6Al-4V at very high strain rates, Scr. Mater. 67 (2012) 229-232.

[11] S.J. Lainé, K.M. Knowles, $\{11 \overline{2} 4\}$ deformation twinning in commercial purity titanium at room temperature, Philos. Mag. 95 (2015) 2153-2166.

[12] G. Lütjering, J.C. Williams, Titanium, 2nd ed., Springer-Verlag, Berlin and Heidelberg, 2007.

[13] G. Taylor, The use of flat-ended projectiles for determining dynamic yield stress. I. Theoretical considerations, Proc. Roy. Soc. Lond. A 194 (1948) 289-299.

[14] R.E. Reed-Hill, Role of deformation twinning in the plastic deformation of a polycrystalline anisotropic metal, in: R.E. Reed-Hill, J.P. Hirth, H.C. Rogers (Eds.), Deformation Twinning, Gordon and Breach, New York, NY, 1964: pp. 295-320.

[15] S.J. Lainé, K.M. Knowles, D. Rugg, Grain boundary interactions of deformation twins in CP titanium after room temperature ballistic testing, in: Proc. 13th World Conf. Titanium, 2016, ed. V. Venkatash, A.L. Pilchak and J.E. Allison, Wiley-TMS, San Diego: pp. 645-650.

[16] W.L. Finlay, J. Resketo, M.B. Vordahl, Optical metallography of titanium, Industrial and Engineering Chemistry 42 (1950) 218-222.

[17] J. Jiang, A. Godfrey, W. Liu, Q. Liu, Identification and analysis of twinning variants during compression of a Mg-Al-Zn alloy, Scr. Mater. 58 (2008) 122-125.

[18] S.I. Wright, M. M. Nowell, EBSD image quality mapping, Microsc. Microanal. 12 (2006) 7284.

[19] M.H. Yoo, Slip, twinning and fracture in hexagonal close-packed metals, Metall. Trans. A 12 (1981) 409-418.

[20] J.W Christian, S. Mahajan, Deformation twinning, Prog. Mater. Sci. 39 (1995) 1-157. 
[21] A. Fitzner, D.G.L. Prakash, J.Q. da Fonseca, M. Preuss, M. Thomas, S.Y. Zhang, J. Kelleher, The effect of aluminium on deformation and twinning in alpha titanium: The $45^{\circ}$ case, Mater. Sci. Forum 765 (2013) 549-553.

[22] A. Fitzner, D.G.L. Prakash, J.Q. da Fonseca, M. Thomas, S.-Y. Zhang, J. Kelleher, P. Manuel, M. Preuss, The effect of aluminium on twinning in binary alpha-titanium, Acta Mater. 103 (2016) 341-351.

[23] A. Serra, R.C. Pond, D.J. Bacon, Computer simulation of the structure and mobility of twinning dislocations in h.c.p. metals, Acta Metall. Mater. 39 (1991) 1469-1480.

[24] N.J. Lane, S.I. Simak, A.S. Mikhayluskin, I.A. Abrikosov, L. Hultman, M.W. Barsoum, First-principles study of dislocations in hcp metals through the investigation of the $\{11 \overline{2} 1\}$ twin boundary, Phys. Rev. B 84 (2011) 184101-1-184101-7.

[25] J. Kacher, A.M. Minor, Twin boundary interactions with grain boundaries investigated in pure rhenium, Acta Mater. 81 (2014) 1-8.

[26] N. Gey, M. Humbert, Specific analysis of EBSD data to study the texture inheritance due to the $\beta \rightarrow \alpha$ phase transformation., J. Mater. Sci. 38 (2003) 1289-1294.

[27] T. Karthikeyan, S. Saroja and M. Vijayalakshmi, Evaluation of misorientation angle-axis set between variants during transformation of bcc to hcp phase obeying Burgers orientation relation, Scr. Mater. 55 (2006) 771-774.

[28] W.G. Burgers, On the process of transition of the cubic-body-centered modification into the hexagonal-close-packed modification of zirconium, Physica 1 (1934) 561-586.

[29] H. Grimmer, Disorientations and coincidence rotations for cubic lattices, Acta Crystallogr. A 30 (1974) 685-688.

[30] H.-J. Bunge, Texture Analysis in Materials Science, Mathematical Methods, Butterworths, London, 1982.

[31] O. Engler, V. Randle, Introduction to Texture Analysis: Macrotexture, Microtexture and Orientation Mapping, 2nd ed., CRC Press, Boca Raton, FL, 2010.

[32] A. Kelly, K.M. Knowles, Crystallography and Crystal Defects, 3rd ed., Wiley, Chichester, UK, 2020. 